\title{
EL CLIMA DE LA CORDILLERA CANTÁBRICA CASTELLANO-LEONESA: DIVERSIDAD, CONTRASTES Y CAMBIOS
}

\author{
Mª Teresa Ortega Villazán y Carlos G. Morales Rodríguez \\ Departamento de Geografía \\ Universidad de Valladolid
}

\section{RESUMEN}

Se realiza la caracterización del clima de la Cordillera Cantábrica en Castilla y León, resaltando los rasgos que la singularizan a partir del análisis de sus variables térmicas y pluviométricas, expresadas de forma numérica y cartográfica. La impronta del relieve, la transición climática zonal y meridiana, y el cambio observado en algunas variables desde los años 90 a la actualidad, son aspectos a destacar.

Palabras clave: Cordillera Cantábrica, Castilla y León, clima, temperaturas, precipitaciones.

\section{ABSTRACT}

\section{The climate of the Castilian-Leonese Cantabrian Mountains: diversity and contrasts}

Climate characterization of the Cantabrian Mountains in Castilla and León is performed, highlighting the features that single out from the analysis of their thermal and rainfall variables, expressed numerically and cartographic. The imprint of the relief, the zonal and meridian climatic transition, and the change observed in some variables from the 90s to the present, are notable aspects.

Key words: Cantabrian Mountains, Castilla and Leon, climate, temperatures, rainfall.

\section{INTRODUCCIÓN}

La Cordillera Cantábrica es un conjunto ininterrumpido de montañas desde Galicia hasta el País Vasco, a lo largo de una alineación de $480 \mathrm{Km}$ que recorre las comunidades autónomas de Asturias, Cantabria y Castilla y León. Su disposición cubre prácticamente todo el límite norte de España, introduciendo un acusado contraste entre lo que se ha venido llamando la Iberia Húmeda y la Iberia Seca (Figura 1). Su vertiente norte es una estrecha fachada azotada por los vientos marinos recubierta de vegetación atlántica, mientras que la meridional es un amplio espacio de transición climática con taxones submediterráneos o subatlánticos. Pero el contraste es también morfológico. Mientras la primera apenas dista del mar unas decenas de kilómetros (40-50 Km), salvándose desde la divisoria un fuerte desnivel de más de $2.500 \mathrm{~m}$, aguas a Castilla el descenso es mucho menor $(1.500 \mathrm{~m})$ en una distancia rayana al centenar de kilómetros.

Posee un carácter de marginalidad respecto a los grandes macizos centroeuropeos, ya que forma la proa suroccidental del arco alpino, el último gran macizo montañoso de Europa antes del Atlántico, localizada en una posición muy meridional. Esto le otorga una gran singularidad pues es la única montaña oceánica de la Península Ibérica. Puede que algunos paisajes atlánticos prosigan con menor entidad por el sur pirenaico o de forma aislada en otras cadenas del centro peninsular, pero en ningún lugar como en ella.

Sus límites están bien marcados al norte (costa cantábrica) y sur (llanuras castellanas), pero no así lateralmente. Al oeste se entrevera con el Macizo Galaico Hespérico, y al este con la cobertera mesozoica plegada de los Montes Vascos que se digita para dar relevo a los Pirineos. Pese a ser una de las cordilleras más elevadas de nuestro país, a nivel mundial su altitud es moderada, pues en ningún caso supera los $3.000 \mathrm{~m}^{1}$. En ella más destaca la disposición de sus estructuras que su altitud, y de ésta, su mantenimiento

Contacto: Ma Teresa Ortega Villazán: maite@fyl.uva.es; Carlos G. Morales Rodríguez: cmorales@fyl.uva.es

1 Sus cotas más altas rayan los 2.500-2.600 m en su sector centro-oeste: Torrecerredo 2.648 m, Torre del Llambrión 2.642 m, Torre del Tiro Tirso $2.641 \mathrm{~m}$, Torre Blanca 2.619 m, Peña Vieja 2.617 m, Torre Santa 2.598 m, Peña Prieta 2.538 m, Curavacas 2.520 m, Naranjo de Bulnes o Picu Urriellu $2.519 \mathrm{~m}$.. 


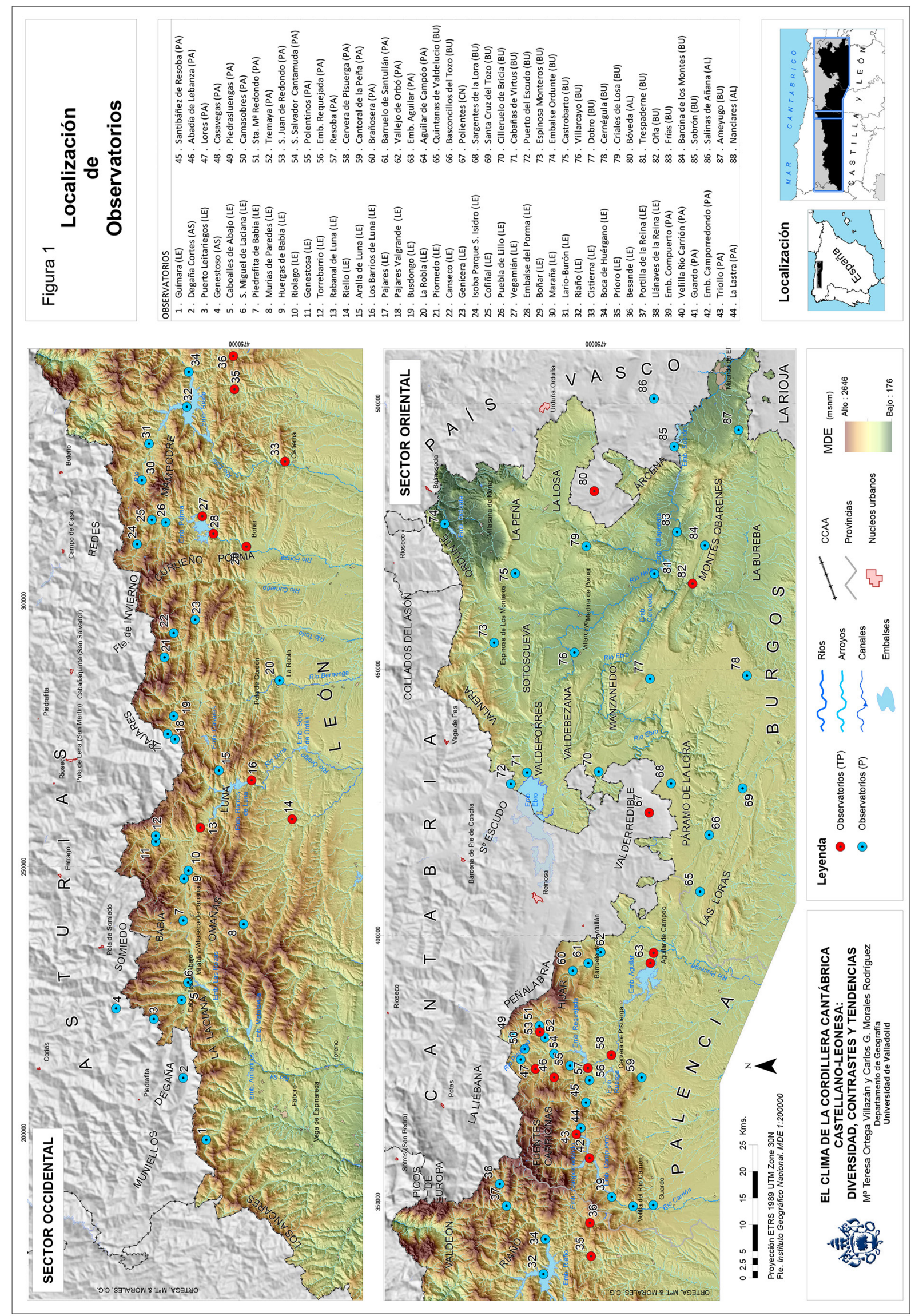


en una prologada extensión, lo que contribuye a generar unos rasgos climáticos propios, si bien no exento de transiciones y matices.

Para este estudio se ha partido de la información de 88 observatorios térmicos y 190 pluviométricos repartidos de forma homogénea y representativa a lo largo de toda la cordillera. La inconsistencia de los datos, su irregularidad en el registro y la brevedad de algunas series, ha sido algo habitual en algunas estaciones. Ello ha obligado a contar sólo con la información de 22 térmicos y 88 pluviométricos, (Figura 1). Aun así esa información no ha sido descartada y se ha utilizado para validar la ofrecida por los más fiables (series más prolongadas y coincidentes).

Es evidente el fuerte desequilibrio numérico que existe entre ambos, al igual que en la información diaria con que cuentan. Mientras las series de precipitación abarcan desde la década de los 30/40 hasta la actualidad (2010), las de temperatura no llegan muchas a los años 90, habiéndose reducido hoy día bastante su número por la creación de estaciones automatizadas (con series cortas). Esto justifica lógicamente el tratamiento más pormenorizado de las precipitaciones.

Algunas series han sido completadas por procedimientos de regresión múltiple por pasos sucesivos, con al menos tres observatorios con afinidad geográfica (por proximidad, altitud y exposición), pero sólo se han utilizado cuando así lo ha permitido el subsiguiente análisis de residuos.

Tras la depuración y completado de los datos, se han homogeneizado las series a partir de la metodología establecida por Alexandersson y Moberg (1997). No obstante, se pretende ante todo analizar el comportamiento de los valores medios, más que un cálculo de tendencias temporales de las variables termopluviométricas, pues como se ha dicho, las características de la información ha impedido obtener unos resultados estadísticos robustos que permitieran detectarlas a un nivel de significación aceptable.

Para la construcción de la cartografía varios han sido los procedimientos utilizados. La información termopluviométrica se ha correlacionado con los valores de longitud, latitud y altitud $(x, y, z)$, de cada observatorio. Mediante regresión múltiple se han construido los modelos digitales del terreno para cada variable, rasterizando la correlación mediante álgebra de mapas utilizando la calculadora ráster de ArcMap, por sectores espacialmente más homogéneos (tres para la mitad occidental y dos para la oriental). Asimismo, cuando los coeficientes de correlación han sido significativos, se han calculado los gradientes para cada uno de esos tramos.

Las tendencias espaciales se han determinado a partir de técnicas de interpolación polinómica para detectar patrones espaciales. La elaboración final se ha basado en estos cálculos y su corrección digital posterior, mediante procedimientos de generalización (para simplificar y suavizar las coropletas), según la correlación de más peso y ajustándose a valores de exposición y orientación.

El objetivo de esta investigación es analizar desde un punto de vista geográfico el clima de una extensa área de la Cordillera Cantábrica, caracterizando, fundamentando y resaltando su comportamiento climático general, sus singularidades y algunos cambios detectados en las últimas décadas.

\section{EL RELIEVE DE LA CORDILLERA Y SU INFLUENCIA EN EL CLIMA}

Su marcada disposición zonal le imprime una gran unidad orográfica, aunque desde el punto de vista geológico se reconocen tres sectores: El occidental, en el límite entre Asturias y Galicia, de menores elevaciones y sin presencia de cobertera mesozoica; el central, de mayores relieves, con el Macizo Asturiano; y el oriental, dominio vasco-cantábrico, con fuertes espesores de cobertera mesozoica que rara vez superan los $1.500 \mathrm{~m}$. Sin embargo, desde el punto de vista climático su individualización es diferente.

Por su situación se ve afectada por los vientos del Oeste quedando la mayor parte del año bajo el influjo del Frente Polar que genera tipos de tiempos inestables. El paso de borrascas es muy frecuente, y esta cordillera se aprovecha de ello. Aunque acusa el balanceo estacional del vórtice circumpolar y la llegada del verano acreciente el influjo del aire tropical marino (Azores), la cordillera no permanece al margen de la inestabilidad que se desarrolla más al norte. La habitual nubosidad, la frecuencia de nieblas y lluvias así lo confirman. Su localización respecto a los vientos del oeste (limite meridional) cobra toda su importancia en verano, pues continúa comportándose como activa pantalla condensadora de humedad.

La proximidad al Cantábrico le condiciona bastante, sobre todo en su fachada septentrional donde las precipitaciones son más constantes, las temperaturas más templadas, las nevadas más reducidas y la innivación mucho menor. El influjo marino atemperante la hace ser una montaña oceánica, pero además marca el límite de la España atlántica (J. Mounier 1979b). Climáticamente, esta barrera se comporta como un importante umbral ecológico, pues dificulta el paso a la circulación del norte, obstaculiza las 
influencias del mar, interfiere en la dinámica atmosférica y ayuda a individualizar el clima de las llanuras de Castilla y León.

Pero lo que realmente distingue a su clima deriva de su configuración morfológica, pues al fin y al cabo los rasgos atmosféricos y el influjo marino son comunes a otros muchos territorios. La estructura del relieve y sus disposiciones (juego de peñas y valles) marcan sus atributos climáticos apareciendo una gran variedad de situaciones topoecológicas y hasta de fuertes contrastes. Y uno de ellos es el que se establece entre las dos mitades que se individualizan a partir del virtual meridiano de Cervera de Pisuerga. En el sector occidental la montaña de las Altas Peñas (Montañas de León y Montaña Palentina), en el sector oriental la Montaña media (Montañas de Burgos, Paramera, Loras y Montes Obarenes).

La mitad occidental está estructurada en grandes moles de relieves apitonados (las Peñas) y profundos valles (Liébana, Valdeón, Sajambre hacia el norte; Prioro, Riaño y Valdeburón hacia el sur), lo que la hace ser una montaña compartimentada, una muralla aportillada que de oeste a este y según vertientes $(\mathrm{N} / \mathrm{S})$ se reconocen diferentes tramos: Muniellos-Degaña/LaLaciana; Somiedo/Babia-Omañas-Luna; Pto. Pajares (montaña central astur-leonesa); Fuentes de Invierno-S.Isidro/Curueño-Porma; Redes/Mampodre; Covadonga/Riaño; Picos de Europa; La Liébana/Fuentes Carrionas; Peñalabra-Campóo/Híjar-Brañosera. Este sector posee los rasgos de un clima de alta montaña, siendo un espacio de alta peligrosidad climática. Las precipitaciones son mayores, las nevadas más copiosas y duraderas, las temperaturas más bajas, y la aridez estival no existe.

La mitad oriental es menos enérgica (rara vez supera los $1.300 \mathrm{~m}^{2}$ ), donde una sucesión de diferentes unidades de relieve se dan relevo de oeste a este. Desde el Páramo de la Lora y las Loras, se pasa a las Montañas de Burgos (tierra de Merindades) con los Montes Valnera al norte y los Obarenes al sur, para tras cruzar la depresión de Miranda de Ebro llegar a los Montes Vascos (Figura 1). Aquí el clima de montaña se atenúa. Las precipitaciones se reducen en sentido zonal y meridiano, las nevadas no son tan abundantes, los rigores del frío se atemperan y aparece la aridez estival. Es un área donde se entreveran condiciones climáticas y ecológicas diversas (atlánticas y mediterráneas), lo que le da una mayor complejidad, ambigüedad e inseguridad al tiempo, erigiéndose en un área de marcada transición climática (Ortega, 1974).El clima depende mucho de su localización a sotavento de las altas peñas.

\section{CONTRASTES TÉRMICOS A LO LARGO DEL AÑO Y ESPACIALMENTE}

Un rasgo significativo de su clima es el frío que se padece la mayor parte del año, y del que es responsable tanto el propio relieve como su situación interior, de espaldas al influjo del mar. Baste cotejar las temperaturas medias anuales a uno y otro lado de la divisoria. Mientras en Asturias superan los $13^{\circ} \mathrm{C}$ (Espinama $13,0^{\circ} \mathrm{C}$; la Hermida $15,1^{\circ} \mathrm{C}$; Tama $14,4^{\circ} \mathrm{C} \ldots$ ), en el interior alcanzan $5-6^{\circ} \mathrm{C}$ en algunos puertos (Leitariegos $5^{\circ} \mathrm{C}$; Isoba-San Isidro $5,8^{\circ} \mathrm{C}$ ), y $8-9^{\circ} \mathrm{C}$ en la mayoría de los valles de su mitad occidental. Sólo superan los $10^{\circ} \mathrm{C}$ sus estribaciones meridionales (La Robla $10,3^{\circ} \mathrm{C}$; Cistierna $10,7^{\circ} \mathrm{C}$; Aguilar $10^{\circ} \mathrm{C}$ ) y su mitad oriental (Quintanas de Valdelucio $10,6^{\circ} \mathrm{C}$; Polientes $11,5^{\circ} \mathrm{C}$; Oña $11,2^{\circ} \mathrm{C}$; Bóveda $11,0^{\circ} \mathrm{C}$; Criales de Losa $12,7^{\circ} \mathrm{C}$ ). Es evidente la mayor rigurosidad térmica aguas al Duero, pero dichos valores encubren un contraste estacional fuertemente desequilibrado.

\subsection{Unos inviernos de montaña, muy rigurosos y largos}

Son los principales caracteres de los inviernos de la Cordillera. Las temperaturas son las propias de un clima de montaña, sobre todo hacia las cumbres pues los valles no dejan de ser espacios al abrigo, aunque a veces en ellos el frío se siente con igual rigurosidad por las inversiones térmicas. Las medias de enero (Cuadro 1, Figura 2) oscilan entre $0-2^{\circ} \mathrm{C}$ en los valles, pero por encima de los $1.300 \mathrm{~m}$ son negativas. En sus estribaciones meridionales superan los $2^{\circ} \mathrm{C}$ (como al norte de la Cuenca), y en su sector más oriental $\operatorname{los} 3^{\circ}-4^{\circ} \mathrm{C}$. El gradiente térmico en sentido zonal es evidente.

Las temperaturas a diario son bajas pues el calentamiento no es intenso ni mantenido. El sol al estar bajo sobre el horizonte trasmonta con prontitud y no penetra bien en los fondos de valle, que sólo disfrutan de unas pocas horas de luz. En ocasiones, los desniveles que median entre cimas y valles impulsan al aire frío a descender al atardecer, acumulándose durante la noche en los sectores bajos creando heladas que permiten la formación de nieblas. Es un proceso motivado por el relieve.

2 Principales cotas: Peña Amaya 1.370 m; Peña Corva 1.333 m; Humión 1.436 m; Castro Valnera 1.718 m; Gorbea 1.481 m; Codés 1.414 m; Aralar/Irumugarrieta $1.427 \mathrm{~m}$.. 


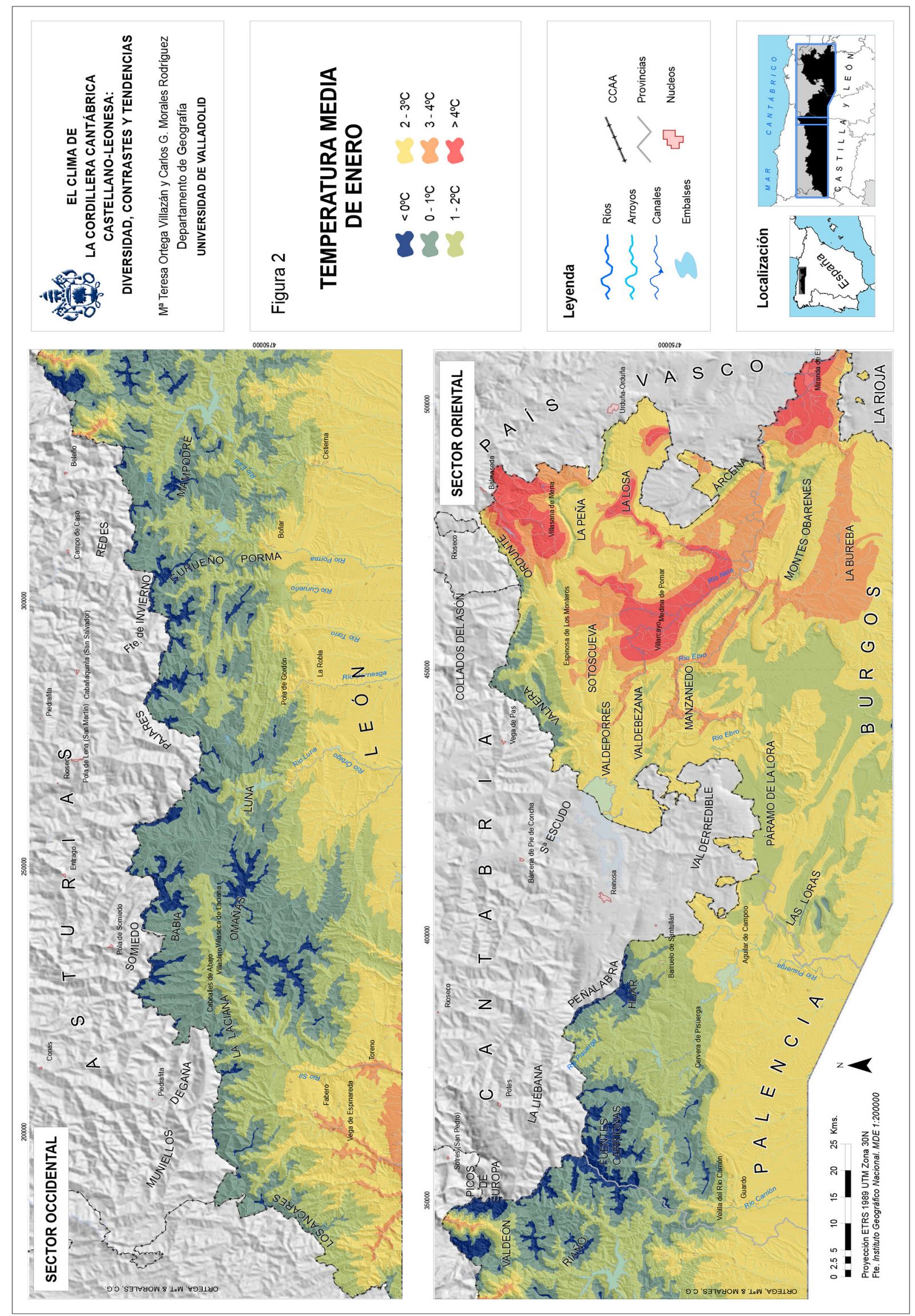


Cuadro 1. Temperaturas medias de enero

OESTE DE CERVERA DE PISUERGA

\begin{tabular}{|c|c|c|c|c|c|c|c|}
\hline \multicolumn{2}{|c|}{$\begin{array}{c}\text { Cimeras, Puertos } \\
>1.300 \mathrm{~m}\end{array}$} & \multicolumn{2}{|c|}{$\begin{array}{c}\text { Valles } \\
1.200-1.300 \mathrm{~m}\end{array}$} & \multicolumn{2}{|c|}{$\begin{array}{c}\text { Valles } \\
1.000-1.200 \mathrm{~m}\end{array}$} & \multicolumn{2}{|c|}{ Estribación meridional } \\
\hline \multicolumn{2}{|c|}{$<0^{\circ} \mathrm{C}$} & \multicolumn{2}{|l|}{$0-1^{\circ} \mathrm{C}$} & \multicolumn{2}{|c|}{$1-2^{\circ} \mathrm{C}$} & \multicolumn{2}{|l|}{$>2^{\circ} \mathrm{C}$} \\
\hline Leitariegos & $-1,0^{\circ} \mathrm{C}$ & Murias Paredes & $0,9^{\circ} \mathrm{C}$ & Barrios Luna & $1,6^{\circ} \mathrm{C}$ & Riello & $2,1^{\circ} \mathrm{C}$ \\
\hline Isoba/S. Isidro & $0,1^{\circ} \mathrm{C}$ & Aralla de Luna & $0,6^{\circ} \mathrm{C}$ & Cofiñal & $1,3^{\circ} \mathrm{C}$ & La Robla & $2,6^{\circ} \mathrm{C}$ \\
\hline Torrebarrio & $0,2^{\circ} \mathrm{C}$ & Maraña & $0,9^{\circ} \mathrm{C}$ & Prioro & $1,7^{\circ} \mathrm{C}$ & Boñar & $2,4^{\circ} \mathrm{C}$ \\
\hline Triollo & $-0,1^{\circ} \mathrm{C}$ & Camporredondo & $0,7^{\circ} \mathrm{C}$ & Pto. Requejada & $1,9^{\circ} \mathrm{C}$ & Cistierna & $2,1^{\circ} \mathrm{C}$ \\
\hline Piornedo & $-0,3^{\circ} \mathrm{C}$ & Lores & $1,0^{\circ} \mathrm{C}$ & Barruelo Sant. & $1,7^{\circ} \mathrm{C}$ & Aguilar Campóo & $2,5^{\circ} \mathrm{C}$ \\
\hline
\end{tabular}

ESTE DE CERVERA DE PISUERGA

\begin{tabular}{|ll|lr|lr|lr|}
\hline \multicolumn{2}{|c|}{ Paramera y Loras } & \multicolumn{2}{c|}{ Montañas de Burgos } & \multicolumn{2}{c|}{ Montes Obarenes } & \multicolumn{2}{c|}{ Montes Vascos } \\
\hline \multicolumn{2}{|c|}{$2-3^{\circ} \mathrm{C}$} & \multicolumn{2}{|c|}{$1-5^{\circ} \mathrm{C}$} & $3-5^{\circ} \mathrm{C}$ & $3-6^{\circ} \mathrm{C}$ \\
\hline Quintanas V. & $2,7^{\circ} \mathrm{C}$ & Puerto del Escudo & $1,6^{\circ} \mathrm{C}$ & Oña & $3,5^{\circ} \mathrm{C}$ & Bóveda \\
\hline Sargentes de L. & $2,3^{\circ} \mathrm{C}$ & Cabañas Virtus & $2,8^{\circ} \mathrm{C}$ & Villarcayo & $4,9^{\circ} \mathrm{C}$ & Salinas Añana & $4,9^{\circ} \mathrm{C}$ \\
\hline Sta. Cruz Tozo & $2,8^{\circ} \mathrm{C}$ & Castrobarto & $4,3^{\circ} \mathrm{C}$ & Miranda Ebro & $4,3^{\circ} \mathrm{C}$ & Nanclares \\
\hline
\end{tabular}

Fuente: AEMET. Delegaciones Territoriales del Duero y País Vasco. Datos medios mensuales.

Las temperaturas medias de las mínimas de enero son igualmente bajas. Hasta el meridiano de Cervera entre -3 y $-5^{\circ} \mathrm{C}$. En el Campóo de Aguilar y las Loras no son muy distintas de las del norte de la región (Aguilar $-2,1^{\circ} \mathrm{C}$ ), pero sí más hacia el este donde les cuesta alcanzar valores negativos (Pto. Escudo $-1,1^{\circ} \mathrm{C}$; Polientes $-0,2^{\circ} \mathrm{C}$; Oña $0,1^{\circ} \mathrm{C}$; Nanclares $1,2^{\circ} \mathrm{C}$ ). Por su parte, las medias de las mínimas absolutas se mantienen durante 8-10 meses negativas (sept./octubre a mayo/junio) en las altas Peñas $\left(-10^{\circ} /-13^{\circ} \mathrm{C}\right.$ en el centro del invierno), y 6-7 meses (nov. a abril/mayo) en el este $\left(-6 /-9^{\circ} \mathrm{C}\right.$ idem). Aunque esta variable carezca de significación, pues no da idea real del frío padecido, sí expresa el mantenimiento de temperaturas muy bajas durante gran parte del año. Lo mismo que al observar los meses en que éstas no superan los $3^{\circ} \mathrm{C}$. Hay enclaves en que no ocurre ningún mes del año (Vegamián, Riaño, Triollo, Lores...).

Las mínimas absolutas rondan los $-20^{\circ} \mathrm{C}$ (Riaño $-23,5^{\circ} \mathrm{C}$; Camporredondo $-25^{\circ} \mathrm{C}$; Triollo $-20,5^{\circ} \mathrm{C}$; Cervera $-20^{\circ} \mathrm{C}$; Lores $-20^{\circ} \mathrm{C}$; Brañosera $-18,6^{\circ} \mathrm{C}$; Villarcayo $-23^{\circ} \mathrm{C}$; Oña $\left.-21^{\circ} \mathrm{C} \ldots\right)$, no apreciándose diferencias pues cuando el frío es intenso se generaliza por toda Castilla y León. Estos bajos registros se asocian a Olas de frío que afectan a la Península con cierta periodicidad (58 años), o a la irrupción de alguna vaguada ártica (aire $\mathrm{Am}$ ) o circulación zonal inversa (retrógrado, aire $\mathrm{Pc}$ ) de carácter anual.

Por su parte, la duración del frío se advierte en el número de meses con medias inferiores a $10^{\circ} \mathrm{C}$. En las Peñas son 8-10 meses (Leitariegos, S.Isidro, Riaño); en sus valles se reduce a 7 (Huergas de Babia, Vegamián, Cofiñal, Cervera), y desde Aguilar hacia el este a 5 o 6. En tan dilatado periodo el frío no se desarrolla de igual manera. Su rigor máximo es de diciembre a febrero (ningún mes supera los $3^{\circ} \mathrm{C}$ ), aunque se amplía a 5 meses (nov. a abril) en la alta montaña. En la mitad oriental, son dos los meses por debajo de $3^{\circ} \mathrm{C}$, y ello en Las Loras y Obarenes, no en territorio alavés.

El frío comienza, según sectores, a lo largo de septiembre o primera decena de octubre, y se prolonga hasta finales de mayo o junio, siendo habitual en todo este tiempo que hiele. El número de días con mínimas inferiores a $7^{\circ} \mathrm{C}$ (criterio de Emberger) es de 300 en muchos puntos (80-85\% del año); el riesgo de heladas $\left(<3^{\circ} \mathrm{C}\right)$ ronda los $200(50-60 \%)$, aunque en las cimeras se produce todo el año; y las heladas reales $\left(<0^{\circ} \mathrm{C}\right)$ afectan a $140-150$ días (35-45\%), unos 5 meses de frío intenso. Más o menos coincide con la duración de la temporada de esquí. Las heladas en verano son esporádicas pues no se producen todos los años y se reservan a enclaves elevados.

Según años y tipo de invierno/primavera existe una gran irregularidad interanual en su producción. Los años templados y húmedos (dominio de circulaciones de alto índice zonal) se reducen bastante, frente aquellos otros más fríos y secos (dominio de circulaciones de bajo índice zonal, advecciones retrógradas, crestas anticiclónicas...). Su periodo de desarrollo es largo, de hecho el frío aunque sea de forma intermitente nunca deja de sentirse en todo el año, si bien caben claras diferencias entre el sector leonés-palentino y el burgalés. Desde los Ancares a Fuentes Carrionas las primeras heladas aparecen en 
septiembre y las últimas en junio. En cambio, desde las Loras a Obarenes se retrasan a octubre o noviembre, y desaparecen a finales de abril o en mayo.

Por último, cabe contempla las temperaturas máximas, por sus valores reducidos, su mantenimiento y el carácter complementario que tienen respecto al resto de los parámetros analizados. Medias por debajo de $15^{\circ} \mathrm{C}$ se producen 6-7 meses (oct./nov. a abril) en las Montañas de León y Palencia, y se reducen a 5 (nov. a marzo) en toda la cobertera mesozoica suroriental. Medias por debajo de $10^{\circ} \mathrm{C}$, tienen lugar de noviembre a febrero en el primer sector, y de diciembre a enero/febrero en el segundo.

Son pues, muchos los días con un tiempo frío lo que hace que el invierno puede delimitarse de octubre a mayo en su mitad occidental y de noviembre a abril en su mitad oriental. Unos inviernos de gran trascendencia en las formas de vida y organización del territorio montañés, al condicionar el desarrollo de la actividad biológica, obligando tanto a la adaptación agrícola, como a la tipología y distribución de la vegetación autóctona. Además, su excesiva prolongación reduce el peso de las estaciones equinocciales. Meses como octubre o mayo/junio siguen siendo de frío, no tan continuo como los centrales pero tan efectivo como entonces. No ocurre así con la llegada del estío. Pese a su brevedad y a no ser muy cálido, es el otro período del año bien definido climáticamente, aunque sea por su disparidad y hasta ambigüedad.

\subsection{Unos veranos de montaña, cortos, frescos y dispares}

La llegada del verano no supone el contrapunto al frío del invierno. Los estíos quedan bastante lejos de la media de $20^{\circ} \mathrm{C}$ que define a los de carácter cálido (Lautensach, 1962). A la mayor parte de la Cordillera le caracteriza la isoterma de $16-18^{\circ} \mathrm{C}$, propia de veranos frescos (Cuadro 2, Figura 3). Por encima de $1.300 \mathrm{~m}$ los veranos son fríos $\left(<13^{\circ} \mathrm{C}\right)$. Tanto a la Paramera, Las Loras y Obarenes les define la isoterma de $18-19^{\circ} \mathrm{C}$ (salvo cimeras $>1000 \mathrm{~m}$ ). En sus límites meridionales rondan los $20^{\circ} \mathrm{C}$, sólo rebasado en los valles de las Montañas de Burgos, Obarenes, y amplias depresiones orientales (Villarcayo, La Bureba).

Cuadro 2. Temperatura media estival (julio y agosto)

OESTE DE CERVERA DE PISUERGA

\begin{tabular}{|c|c|c|c|c|c|c|c|}
\hline \multicolumn{2}{|c|}{$\begin{array}{c}\text { Cimeras, Puertos } \\
>1.300 \mathrm{~m}\end{array}$} & \multicolumn{2}{|c|}{$\begin{array}{c}\text { Valles } \\
1.200-1.300 \mathrm{~m}\end{array}$} & \multicolumn{2}{|c|}{$\begin{array}{c}\text { Valles } \\
1.000-1.200 \mathrm{~m}\end{array}$} & \multicolumn{2}{|c|}{ Estribación meridional } \\
\hline \multicolumn{2}{|c|}{$<16^{\circ} \mathrm{C}$} & \multicolumn{2}{|c|}{$16-17^{\circ} \mathrm{C}$} & \multicolumn{2}{|c|}{$17-18^{\circ} \mathrm{C}$} & \multicolumn{2}{|c|}{$>18^{\circ} \mathrm{C}$} \\
\hline Leitariegos & $11,9^{\circ} \mathrm{C}$ & Murias Paredes & $16,3^{\circ} \mathrm{C}$ & Barrios Luna & $18,4^{\circ} \mathrm{C}$ & La Robla & $18,7^{\circ} \mathrm{C}$ \\
\hline Isoba/S. Isidro & $12,7^{\circ} \mathrm{C}$ & Aralla de Luna & $16,5^{\circ} \mathrm{C}$ & Cofiñal & $16,9^{\circ} \mathrm{C}$ & Boñar & $18,4^{\circ} \mathrm{C}$ \\
\hline Torrebarrio & $15,8^{\circ} \mathrm{C}$ & Maraña & $16,3^{\circ} \mathrm{C}$ & Prioro & $17,5^{\circ} \mathrm{C}$ & Cistierna & $19,1^{\circ} \mathrm{C}$ \\
\hline Piornedo & $15,4^{\circ} \mathrm{C}$ & Camporredondo & $16,1^{\circ} \mathrm{C}$ & Pto. Requejada & $17,8^{\circ} \mathrm{C}$ & Aguilar Campoó & $18,3^{\circ} \mathrm{C}$ \\
\hline
\end{tabular}

ESTE DE CERVERA DE PISUERGA

\begin{tabular}{|ll|lr|ll|l|}
\hline \multicolumn{2}{|c|}{ Paramera y Loras } & \multicolumn{2}{c|}{ Montañas de Burgos } & \multicolumn{2}{c|}{ Montes Obarenes } & \multicolumn{2}{c|}{ Montes Vascos } \\
\hline \multicolumn{2}{|c|}{$19^{\circ} \mathrm{a}>20^{\circ} \mathrm{C}$} & \multicolumn{2}{c|}{$18^{\circ} \mathrm{a}>20^{\circ} \mathrm{C}$} \\
\hline Quintanas V. & $19,6^{\circ} \mathrm{C}$ & Puerto Escudo & $13,9^{\circ} \mathrm{C}$ & Oña & $19,3^{\circ} \mathrm{C}$ & Bóveda \\
\hline Sargentes de L. & $19,1^{\circ} \mathrm{C}$ & Cabañas Virtus & $19,7^{\circ} \mathrm{C}$ & Miranda Ebro & $20,1^{\circ} \mathrm{C}$ & Salinas Añana \\
\hline Sta. Cruz Tozo & $19,7^{\circ} \mathrm{C}$ & Castrobarto & $21,7^{\circ} \mathrm{C}$ & Villarcayo & $22,1^{\circ} \mathrm{C}$ & Nanclares \\
\hline
\end{tabular}

Fuente: AEMET. Delegaciones Territoriales del Duero y País Vasco. Datos medios mensuales.

El verano también es de corta duración. No suele prolongarse más allá de julio y agosto, ya que tanto en junio como septiembre las medias no alcanzan $\operatorname{los} 15^{\circ} \mathrm{C}$ (salvo estribaciones meridionales y orientales). Además, hay una acomodación térmica a la delimitación que aportan las precipitaciones, pues sólo en estos dos meses se produce una merma significativa en sus registros (sin llegar normalmente a la aridez).

Los veranos son frescos por varias razones. Durante el crepúsculo las temperaturas bajan llegándose a sentir frío durante la sonochada. A lo largo de los valles soplan brisas de montaña que permiten la acumulación del aire denso que favorece la formación de nieblas y rocíos. El calentamiento desde el amanecer es lento y progresivo. Las temperaturas medias de las mínimas alcanzan $6^{\circ}-7^{\circ} \mathrm{C}$ en los valles más fríos, y $8^{\circ}-9^{\circ} \mathrm{C}$ en los más abiertos. El sol tarda en calentar el suelo. La sensación de frescor se deja sentir hasta varias horas después. 


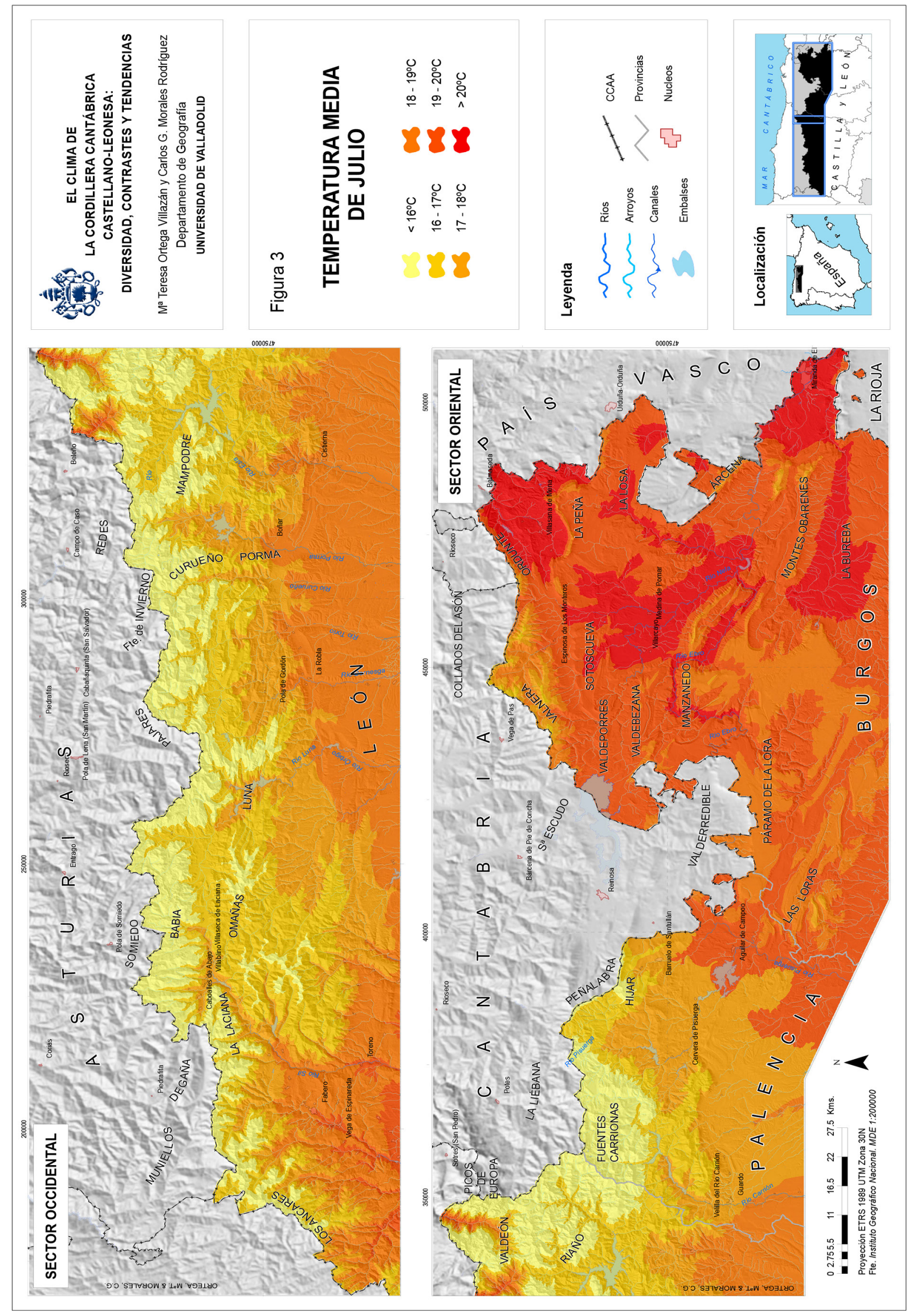


Estos procesos incrementan las oscilaciones térmicas diarias. De mayo a agosto se aquilatan, logrando en junio y julio valores medios de $17^{\circ}-22^{\circ} \mathrm{C}$. Suelen ser más fuertes en las cabeceras de los valles, hacia el interior, que no en la periferia, lo que demuestra que existen ascensos térmicos similares por todo el conjunto montañoso pero descensos nocturnos más acusados donde la altitud es mayor.

Aunque se alcancen temperaturas elevadas, más que un auténtico calor (que también se siente) se perciben contrastes térmicos (entre el día y la noche, el sol y la sombra...), todo ello por efecto de la altitud y sequedad de la atmósfera. Ello dota a los veranos de cierta complejidad y gran parte de culpa la tiene la forma de resolverse la dinámica atmosférica en esta época. Pese a su mayor uniformidad por el ascenso latitudinal de los anticiclones subtropicales y el repliegue del Frente Polar, ni este avance ni ese retroceso son tan nítidos como pueda expresarse. El norte de España queda a merced de la fluctuación de diversos centros de acción y masas de aire, que favorecen la encrucijada de matices atlánticos y mediterráneos, permitiendo la alternancia de días de frío y de calor, siguiendo ese claro juego de contrastes. Y es quizá éste el principal rasgo de los veranos de la Cantábrica, la inseguridad del tiempo.

El frío en el verano se debe tanto a los fuertes descensos térmicos diarios como a las dinámicas específicas que lo generan. Unas veces es el paso de vaguadas polares y árticas que afectan con sus prolongaciones meridionales a todo el Cantábrico, trayendo cielos cubiertos, precipitaciones y nieblas, así como importantes descensos térmicos (en puntos elevados no alcanzan los $10^{\circ} \mathrm{C}$ ). Estas situaciones suelen durar 3 o 4 días, pero de sucederse varias contribuyen a perfilar el carácter fresco de la estación. Otras veces, son crestas tropicales de eje meridiano que afectan perpendicularmente con su zona de salida a la cordillera generando vientos del norte muy húmedos que al ascender forman nubes estratiformes. Al sobrepasar las divisorias muchos valles (aguas a Castilla) quedan sumidos en una densa niebla. Son las boiras que si no ocasionan lluvias sí que mojan el suelo, impidiendo la radiación solar.

Valores que dan idea del frío que se puede sentir son las medias de las mínimas absolutas, entre $1^{\circ}-3^{\circ} \mathrm{C}$ en la mitad occidental, y por encima de $3^{\circ} \mathrm{C}$ desde Cervera a los Montes Vascos; o las mínimas absolutas, con $0^{\circ} \mathrm{C}$ o valores negativos en su mitad occidental, y no precisamente a elevadas altitudes (Camporredondo $-3,5^{\circ} \mathrm{C}$, Lores $-1,9^{\circ} \mathrm{C}$, Cervera $-1,0^{\circ} \mathrm{C}$; frente a $2,2^{\circ} \mathrm{C}$ de Aguilar o $3,5^{\circ} \mathrm{C}$ de Oña). Esto evidencia que en verano puede helar. De hecho, las mantas no se quitan de las camas en todo el año.

En la mitad oriental los días cálidos y despejados son más habituales, lo que ha motivado desde siempre una importante afluencia de vascos al entorno de las Montañas de Burgos y Obarenes. Y es que el calor, también existe. Las crestas Tm permiten ascensos de $25-28^{\circ} \mathrm{C}$ en los valles, aunque sea en las horas centrales del día. Son los días espléndidos de la montaña. Más ocasionalmente se alcanzan $30^{\circ}-35^{\circ} \mathrm{C}$, ligado a crestas saharianas continentales (Tc) de marcada penetración sureña que enturbian los cielos durante varias jornadas, creando bochorno. Son situaciones poco frecuentes, que apenas alcanzan una media de 5 días/verano en la Montaña leonesa y palentina, pero que se incrementan hacia el este (Oña 16,8 días; Miranda de Ebro 19,2). Las máximas absolutas rondan los $34^{\circ}-36^{\circ} \mathrm{C}$, no alcanzando nunca los $40^{\circ} \mathrm{C}$ (Camporredondo y Triollo $37^{\circ} \mathrm{C}$; Aguilar 39, $6^{\circ} \mathrm{C}$; Oña $39,9^{\circ} \mathrm{C}$ ), ligadas a Olas de calor.

Resulta claro el desigual comportamiento de los estíos entre la Cantábrica leonesa y palentina, con veranos frescos (de montaña), y la burgalesa, con veranos más ambiguos, con menos certeza en el tiempo. Pero esta forma de manifestarse las temperaturas también se pone de manifiesto al analizar las precipitaciones.

\section{EL REPARTO DE LAS PRECIPITACIONES. LA VINCULACIÓN AL RELIEVE}

La verdadera singularidad del clima en la cordillera viene dada por las precipitaciones. Son las propias de un área de montaña, pero del norte de España. En ellas se aprecia tanto un reparto zonalizado O-E (de muy húmedo a más seco), como otro meridiano N-S (más húmedas las vertientes asturianas que las castellanas). Totalmente dependientes del relieve y de su localización en la vertiente sur, es un espacio bien individualizado, no tan lluvioso como las cumbres asturianas, pero lo suficientemente húmedo como para destacarse de las llanuras castellanas.

Hace tiempo fue evaluado el máximo pluviométrico para altitudes superiores a $2.000 \mathrm{~m}$ en $2.500 \mathrm{~mm}$ (Jansá, 1971: 246), pero este umbral se reduce a partir de Cervera a $1.4001 .500 \mathrm{~mm}$. Es evidente la progresiva desecación del aire hacia el sur y el este, tanto por la pérdida de altitud, como por su localización más interior. Sin embargo, esto no impide reactivaciones en las masas de aire cada vez que remontan obstáculos montañosos (Las Loras, Obarenes, Valnera...). Así, la disminución pluviométrica en sentido zonal y meridiano no es tan lineal ni clara, debido a la complejidad del relieve. 
Los índices medios mensuales muestran diferencias espaciales que afectan tanto a la cuantía anual como a la forma de distribuirse a lo largo del año (Cuadro 3, Figura 4). Las áreas más húmedas de León son las divisorias de Degaña y Laciana, que dan cobijo a las cabeceras del Cúa y Sil, entre los puertos de Cinfuegos $(1.686 \mathrm{~m})$, Leitariegos $(1.525 \mathrm{~m})$ y Somiedo $(1.486 \mathrm{~m})$. En este tramo las cumbres rayan los $2.000 \mathrm{~m}$, y están muy bien expuestas lo que permite alcanzar casi los $2.000 \mathrm{~mm}$ anuales.

Sobre las altas Peñas de la Babia (Peñas Chana, Orniz, Rueda, Ubiña), entre los puertos de Somiedo y Cubilla, cabecera del río Luna, las precipitaciones son igualmente abundantes, si bien sobre la vertiente sur de tan inconsútil muro hay una gran reducción en el fondo del valle (Babia Baja, 1.000-1.100 mm). Avanzando hacia el este, entre los puertos de Pajares y Piedrafita, cabeceras del Bernesga y Torío, los portillos son más frecuentes con lo que el paso del aire hacia Castilla no se ve tan impedido permitiendo volúmenes de 1.300-1.700 mm en los altos valles de cabecera (Canseco, Piornedo).

Entre los puertos de Vegarada y Tarna, pasando por el de San Isidro se levantan las peñas de Fuentes de Invierno, $S^{a}$ del Ajo, Porrones de Moneo, $S^{a}$ de Mongayo y la "Reserva Nacional de Mampodre", cabeceras de los ríos Curueño y Porma. Su divisoria aunque siempre supera los $2.000 \mathrm{~m}$, recoge precipitaciones entre $1.400-1.600 \mathrm{~mm}$.

Cuadro 3. Precipitaciones medias anuales (mm)

OESTE DE CERVERA DE PISUERGA

\begin{tabular}{|c|c|c|c|c|c|c|c|c|c|c|}
\hline \multicolumn{11}{|c|}{ Montaña de León } \\
\hline \multicolumn{2}{|c|}{ Degaña/Laciana } & \multicolumn{2}{|l|}{ Babia } & \multicolumn{2}{|c|}{ Pajares/Piedrafita } & \multicolumn{3}{|c|}{ R. N. Mampodre } & \multicolumn{2}{|c|}{ Picos de Europa } \\
\hline Degaña & 1969,7 & Genestosa & 1094,6 & Pajares & 1774,4 & \multicolumn{2}{|c|}{ Isoba-S.Is. } & 1516,0 & Llánaves R. & 1264,9 \\
\hline Leitariegos & 1601,1 & Piedrafita & 1084,4 & Busgongo & 1055,9 & \multicolumn{2}{|c|}{ Cofiñal } & 1535,2 & Lario-Burón & 1457,8 \\
\hline Guímara & 1765,5 & Torrebarrio & 1022,2 & Piornedo & 1504,8 & \multicolumn{2}{|c|}{ Puebla Lillo } & 1422,7 & Boca de $\mathrm{H}$. & 1258,0 \\
\hline Caboalles & 1786,0 & Huergas B. & 1094,5 & Canseco & 1456,8 & \multicolumn{2}{|c|}{ Maraña } & 1474,4 & Prioro & 1289,4 \\
\hline \multicolumn{11}{|c|}{ Montaña Palentina } \\
\hline \multicolumn{3}{|c|}{ Fuentes Carrionas } & \multicolumn{4}{|c|}{ La Pernía } & \multicolumn{4}{|c|}{ Braña/Híjar } \\
\hline \multicolumn{2}{|l|}{ Triollo } & 1009,7 & \multicolumn{2}{|c|}{ Piedrasluengas } & \multicolumn{2}{|c|}{1052,1} & \multicolumn{3}{|c|}{ Brañosera } & 1118,8 \\
\hline \multicolumn{2}{|l|}{ La Lastra } & 1109,2 & \multicolumn{2}{|c|}{ Camasobres } & \multicolumn{2}{|c|}{1025,5} & \multicolumn{3}{|c|}{ Barruelo de Santullán } & 904,4 \\
\hline \multicolumn{2}{|c|}{ Emb. Camporredondo } & 1120,6 & \multicolumn{2}{|l|}{ Lores } & \multicolumn{2}{|c|}{1163,5} & \multicolumn{3}{|c|}{ S. Salvador de Cantamudá } & 975,9 \\
\hline \multicolumn{2}{|c|}{ Emb. Compuerto } & 1114,8 & \multicolumn{2}{|l|}{ Tremaya } & \multicolumn{2}{|c|}{1137,9} & \multicolumn{3}{|l|}{ Orbó } & 742,2 \\
\hline
\end{tabular}

ESTE DE CERVERA DE PISUERGA

\begin{tabular}{|lr|lr|lr|ll|}
\hline \multicolumn{4}{|c|}{ Montañas de Burgos } & \multicolumn{2}{c|}{ Montes Vascos } \\
\hline \multicolumn{2}{|c|}{ Paramera/ Loras } & \multicolumn{2}{c|}{ Merindades } & \multicolumn{2}{c|}{ Montes Obarenes } & \multicolumn{2}{c|}{ Árcena/Valderejo } \\
\hline Polientes & 800,2 & Pto. del Escudo & 1626,0 & Barcina Montes & 784,5 & Sobrón & 885,7 \\
\hline Sta. Cruz del Tozo & 723,3 & Pto. Ordunte & 1388,6 & Oña & 674,7 & Bóveda & 829,0 \\
\hline Sargentes la Lora & 700,3 & Cabañas Virtus & 1090,4 & Trespaderne & 682,9 & Salinas de Añana & 700,0 \\
\hline Dobro & 739,5 & Castrobarto & 986,0 & Frías & 694,6 & Nanclares & 735,9 \\
\hline
\end{tabular}

Fuente: AEMET. Delegaciones Territoriales del Duero y País Vasco. Datos medios mensuales.

Desde el puerto de Ventaniella hasta el de San Glorio, aparecen los Picos de Europa con sus macizos de Cornión y los Urrieles. El primero delimita la montaña de Covadonga de la de Sajambre (cabecera del Sella) y Valdeón (alto Cares), destacando las Peñas Santas (de Castilla 2.596 m y de Enol 2.478 m). El segundo, entre el Cares y el Duje, parte central, es menos extenso pero de mayor altitud (Torrecerredo, $2.648 \mathrm{~m}$ ). Hacia el sur se continua la divisoria por Torre Bermeja, Pico Tesorero y Torre Blanca para ir disminuyendo progresivamente hasta San Glorio (1.609 m). En todas estas peñas las precipitaciones son abundantes, pero no como en el Macizo Asturiano. En el entorno a Riaño rondan los 1.200-1.500 mm. El macizo de Picos crea un efecto de "sombra pluviométrica" ante los frentes del NO tanto en los valles cántabros (Baró y Liébana) como en los leoneses (Cares y Reina), afectando más directamente a Peña Prieta, al sur.

A pocos kilómetros comienza la Montaña palentina (Peña Prieta, Tres Provincias, Ftes. Carrionas, Pico Murcia, Curavacas y Espigüete), el sector más noroccidental de la "R. N. de Fuentes Carrionas" 


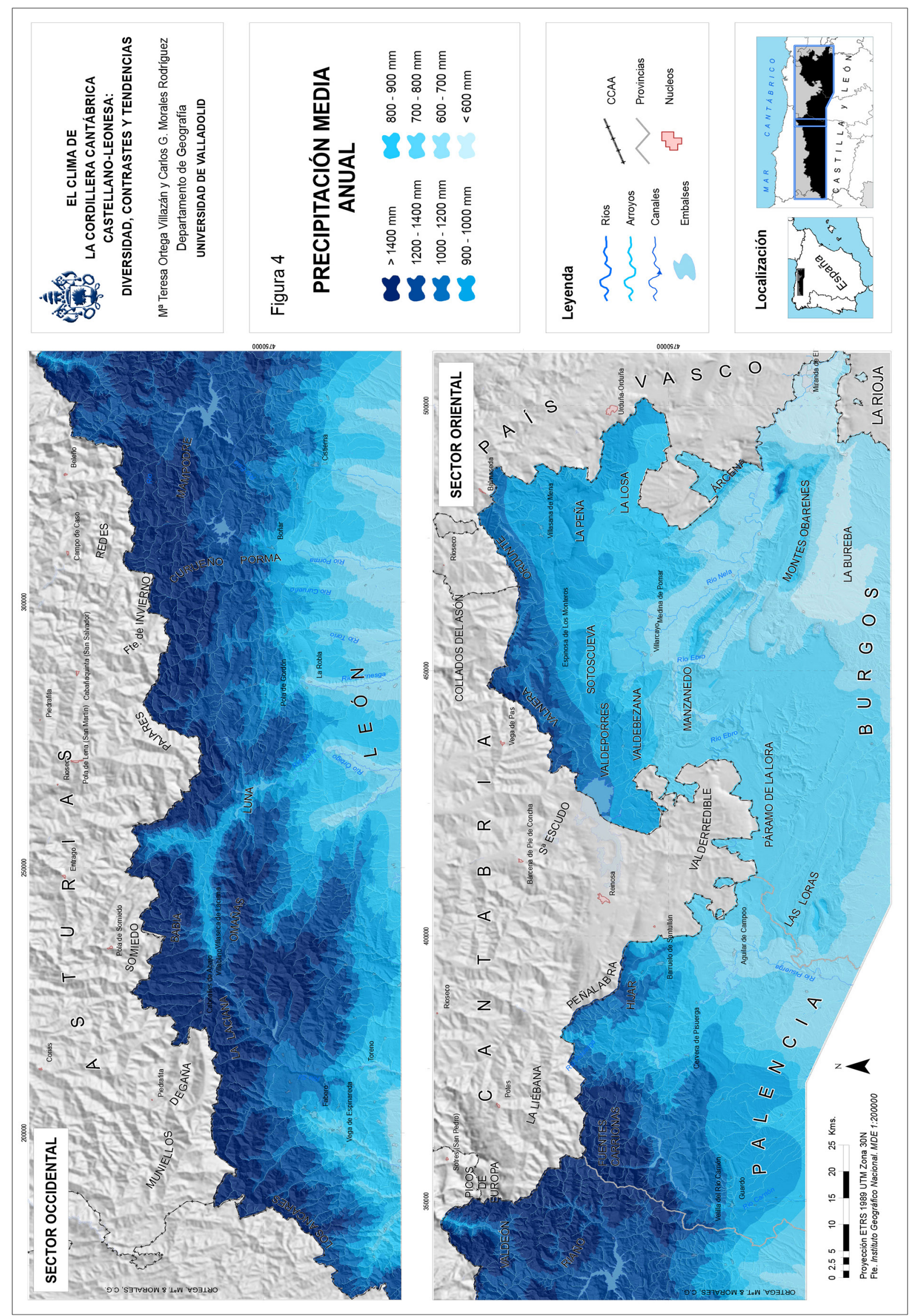


cabecera del Carrión. Su posición más adentrada y precedida por Picos justifica su menor cuantía pluviométrica. Salvo en las altas peñas, los promedios se reducen a 1.000-1.200 mm (Triollo, Camporredondo). Pero este descenso se acusa aún más en el inmediato valle del Pisuerga, en la Pernía, delimitada por las $S^{a}$ Albas, Peña Labra e Híjar, de altitudes más comedidas. No en vano son las últimas altas peñas de un espacio que comienza a estar a sotavento. Ya desde el río Rubagón hacia el este descienden por debajo de los $1.000 \mathrm{~mm}$ (Barruelo, Orbó). Por eso el meridiano de Cervera marca perfectamente la transición climática.

Las precipitaciones en la mitad oriental de la cordillera cambian, siendo su distribución más heterogénea al entreverarse valores muy dispares. En la divisoria de Valnera (Castrovalnera $1.717 \mathrm{~m}$; Peña Negra $1.605 \mathrm{~m}$ ), y Ordunte $(1.104 \mathrm{~m}$ ), se superan los $1.500 \mathrm{~mm}$ (Pto. del Escudo), y aún en el pasillo de Espinosa de los Monteros y en el Valle de Mena se mantienen entre 1.000-1.400 mm. Esto se debe a que entre Valnera y los Pirineos hay un umbral deprimido que tiene un peculiar comportamiento respecto a la dinámica atmosférica. Es una importante vía de paso del aire húmedo de procedencia norteña ( $\mathrm{N}$ y $\mathrm{NE}$ ), muy eficaz incluso en verano. La disposición zonal de la Cantábrica y Pirineos con el umbral del País Vasco, unido al efecto de succión producido por la región ciclogenética mediterránea, explican la mayores precipitaciones en la costa vasca (S. Sebastián $1.524 \mathrm{~mm}$, frente a 980 mm de Gijón, [Uriarte, 1980: 106]).

Desde esta divisoria hacia el sur se produce una tamización que alcanza sus índices más bajos en las depresiones de la Bureba y Miranda ( $<500 \mathrm{~mm}$ ). No obstante, es una gradación compleja. En este descenso meridiano destacan una serie de sierras (Loras, Tesla, Tablones, Oña, Árcena, Humión...), que reactivan las masas de aire. Son los segundos o terceros barloventos que remontan, lo que permite descargas aún importantes (>1.000 mm en la S de Árcena y Humión). En Tesla y desde la Mesa de Oña al Castillete de Pancorvo, se reducen a 800-900 mm, índices parejos a los de las partes más elevadas de las Loras y el Páramo de la Lora (Ortega, 1990: 58).

En general, a 800-1000 m las medias son de 700-800 mm, pero por debajo del primer umbral la reducción es indudable. Mientras en las depresiones y gargantas más septentrionales (Trespaderne, Cereceda, Ranera, Valderrama, Oña, Frías-Tobera o Pancorvo) rondan los 600-700 mm, en las más meridionales (Caderechas, contacto a la Bureba), los 500-600 mm. Por lo tanto, este sector suroriental marca bien la transición climática del dominio atlántico al mediterráneo. Pero si peculiar es la distribución espacial de esta variable, más aún la forma que tiene de hacerlo a lo largo del año.

\subsection{El régimen pluviométrico y su distribución según períodos temporales}

Los regímenes pluviométricos indican que las precipitaciones se producen a lo largo de todo el año. Incluso en verano hay registros de variado sesgo (de abundantes a moderados) según el sector de la montaña. Pero esta aparente uniformidad encubre un comportamiento que no es en absoluto homogéneo en toda la cordillera. Aunque hay un claro predominio del régimen invernal, son varios los matices que se pueden establecer. En el Macizo Astur-Leonés, aun siendo abundantes todo el año, tienen mayor importancia de octubre a mayo. El régimen es de otoño-invierno, con máximo en diciembre (Degaña, Laciana, Babia, Piedrafita). Las precipitaciones a partir de octubre superan los $100 \mathrm{~mm}$ de media mensual, manteniéndolo hasta abril/mayo. En los lugares mejor expuestos incluso son 5 los meses que superan $200 \mathrm{~mm}$ (Degaña, Lena Boca Negrón). El repunte primaveral apenas se aprecia, siendo más evidente en la parte oriental de la cordillera. Destaca que en la salida de la montaña, siempre el máximo mensual es en enero (Riello, La Robla, Cistierna, Guardo, Cervera).

A partir de Mampodre, en la $S^{a}$ de Riaño, Picos y Ftes. Carrionas, el régimen sigue siendo de otoño-invierno pero con máximo de noviembre. Tendencia más palpable en las sierras surorientales (Loras, Paramera, Obarenes, Árcena), excepto en las Montañas de Burgos. Por su parte, el número de meses por encima de $100 \mathrm{~mm}$ se reduce a 6 (octubre a marzo), y sólo un mes alcanza los $200 \mathrm{~mm}$ (en montañas más orientales de León). En las cabeceras del Carrión y Pisuerga cada vez se hace más patente el repunte primaveral.

$\mathrm{Al}$ analizar la evolución de las precipitaciones en los observatorios de series más prolongadas ${ }^{3}$, se observan cambios en las cuantías y en la forma de producirse. Desde 1990 hasta nuestros días existe una reducción importante en los registros de algunos de ellos, sin que haya habido cambio en la toma de datos (Cuadro 4). Bien es cierto que otros se comportan igual. Más llamativo es el cambio que se advierte en el régimen pluviométrico. De ser los meses invernales los más lluviosos, en las últimas décadas se reducen

3 Aunque es evidente el desigual número de años de cada período analizado (hasta 1990, y desde 1990) sí son expresivos los resultados en ambos períodos. 
sus cuantías ganando importancia las precipitaciones otoñales (septiembre y octubre), hasta tal punto que octubre supera los $200 \mathrm{~mm}$ en algunos observatorios. Igualmente se comprueba la reducción de las precipitaciones máximas en ambos períodos, bien se compute el total mensual o en 24 horas. En el primer período siempre muestran umbrales más elevados (Cuadro 5).

Cuadro 4. Evolución de la precipitación según períodos

\begin{tabular}{|c|c|c|c|c|c|c|c|c|c|c|c|c|c|}
\hline Estación & $\mathrm{E}$ & $\mathrm{F}$ & M & A & $\mathbf{M}^{\prime}$ & $\mathrm{J}$ & J' & $A^{\prime}$ & $\mathrm{S}$ & $\mathrm{O}$ & $\mathrm{N}$ & D & Total \\
\hline \multicolumn{14}{|l|}{ Degaña } \\
\hline Hasta 1990 & 225,2 & 247,3 & 165,4 & 179,0 & 170,2 & 94,9 & 76,2 & 58,8 & 80,3 & 244,5 & 202,9 & 353,7 & 2098,3 \\
\hline Desde 1990 & 193,2 & 136,0 & 159,1 & 158,2 & 142,5 & 80,4 & 58,1 & 57,1 & 123,0 & 249,0 & 230,6 & 253,9 & 1841,1 \\
\hline \multicolumn{14}{|l|}{ Canseco } \\
\hline Hasta 1990 & 139,4 & 154,7 & 119,5 & 136,4 & 136,5 & 76,3 & 50,3 & 49,0 & 80,0 & 156,8 & 181,8 & 164,7 & 1445,5 \\
\hline Desde 1990 & 143,6 & 83,8 & 121,6 & 152,7 & 151,6 & 74,3 & 51,0 & 43,6 & 113,0 & 201,8 & 164,8 & 158,8 & 1460,6 \\
\hline \multicolumn{14}{|l|}{ Maraña } \\
\hline Hasta 1990 & 180,9 & 142,1 & 132,5 & 120,4 & 127,8 & 66,2 & 41,3 & 43,9 & 84,4 & 139,3 & 176,3 & 173,6 & 1428,7 \\
\hline Desde 1990 & 167,8 & 121,3 & 144,4 & 145,2 & 126,1 & 61,6 & 37,6 & 46,9 & 81,1 & 185,5 & 215,1 & 187,5 & 1520,1 \\
\hline \multicolumn{14}{|c|}{ Boca de Huérgano } \\
\hline Hasta 1990 & 166,8 & 136,9 & 131,7 & 111,8 & 119,8 & 71,8 & 35,3 & 35,4 & 67,7 & 128,0 & 165,9 & 164,8 & 1335,9 \\
\hline Desde 1990 & 123,5 & 102,3 & 108,1 & 104,6 & 97,9 & 51,9 & 31,0 & 38,3 & 72,3 & 156,7 & 157,9 & 135,5 & 1180,0 \\
\hline \multicolumn{14}{|l|}{ Besande } \\
\hline Hasta 1990 & 190,2 & 178,4 & 163,1 & 138,5 & 135,8 & 87,7 & 43,6 & 37,0 & 87,9 & 158,6 & 221,1 & 204,1 & 1646,0 \\
\hline Desde 1990 & 162,8 & 90,1 & 117,9 & 119,1 & 119,1 & 57,0 & 37,2 & 41,9 & 93,7 & 199,4 & 163,7 & 163,7 & 1365,6 \\
\hline \multicolumn{14}{|l|}{ Triollo } \\
\hline Hasta 1990 & 135,0 & 107,6 & 104,4 & 88,3 & 97,2 & 62,5 & 41,3 & 34,1 & 69,7 & 105,3 & 129,8 & 147,7 & 1122,8 \\
\hline Desde 1990 & 93,6 & 65,8 & 78,8 & 78,3 & 85,7 & 54,0 & 29,7 & 37,4 & 54,5 & 106,1 & 105,4 & 107,1 & 896,5 \\
\hline \multicolumn{14}{|l|}{ Lores } \\
\hline Hasta 1990 & 129,6 & 119,4 & 84,4 & 114,5 & 108,1 & 70,1 & 45,9 & 33,8 & 59,4 & 123,2 & 134,8 & 142,0 & 1165,1 \\
\hline Desde 1990 & 143,4 & 97,0 & 106,1 & 100,9 & 103,4 & 55,1 & 32,6 & 36,8 & 63,5 & 137,2 & 153,6 & 132,2 & 1161,8 \\
\hline
\end{tabular}

Fuente: AEMET. Delegación Territorial del Duero. Datos medios mensuales.

Cuadro 5. Precipitaciones máximas según distintos períodos

\begin{tabular}{|c|c|c|c|c|}
\hline \multirow[t]{2}{*}{ Observatorios } & \multicolumn{2}{|c|}{ Máxima al mes } & \multicolumn{2}{|c|}{ Máxima 24 horas } \\
\hline & Total mensual & Fecha & Total día & Fecha \\
\hline \multicolumn{5}{|l|}{ Degaña } \\
\hline Hasta 1990 & $847,2 \mathrm{~mm}$ & Diciembre 1978 & $126,3 \mathrm{~mm}$ & Diciembre 1978 \\
\hline Desde 1990 & $603,9 \mathrm{~mm}$ & Marzo 2001 & $87,0 \mathrm{~mm}$ & Diciembre 2002 \\
\hline \multicolumn{5}{|l|}{ Canseco } \\
\hline Hasta 1990 & $660,0 \mathrm{~mm}$ & Febrero 1966 & $100,0 \mathrm{~mm}$ & Agosto 1968 \\
\hline Desde 1990 & $429,5 \mathrm{~mm}$ & Marzo 1991 & $92,0 \mathrm{~mm}$ & Octubre 1992 \\
\hline \multicolumn{5}{|l|}{ Maraña } \\
\hline Hasta 1990 & $487,6 \mathrm{~mm}$ & Noviembre 1951 & $118,0 \mathrm{~mm}$ & Abril 1968 \\
\hline Desde 1990 & $429,5 \mathrm{~mm}$ & Octubre 1993 & $112,4 \mathrm{~mm}$ & Diciembre 1996 \\
\hline \multicolumn{5}{|l|}{ Boca de Huérgano } \\
\hline Hasta 1990 & $458,2 \mathrm{~mm}$ & Abril 1983 & $138,0 \mathrm{~mm}$ & Noviembre 1974 \\
\hline Desde 1990 & $421,4 \mathrm{~mm}$ & Diciembre 2000 & $90,4 \mathrm{~mm}$ & Diciembre 2002 \\
\hline \multicolumn{5}{|l|}{ Besande } \\
\hline Hasta 1990 & $725,9 \mathrm{~mm}$ & Diciembre 1959 & $138,0 \mathrm{~mm}$ & Octubre 1987 \\
\hline Desde 1990 & $501,7 \mathrm{~mm}$ & Diciembre 2000 & $115,4 \mathrm{~mm}$ & Febrero 2001 \\
\hline \multicolumn{5}{|l|}{ Triollo } \\
\hline Hasta 1990 & $431,2 \mathrm{~mm}$ & Noviembre 1951 & $113,0 \mathrm{~mm}$ & Enero 1941 \\
\hline Desde 1990 & $353,1 \mathrm{~mm}$ & Diciembre 2000 & $71,1 \mathrm{~mm}$ & Diciembre 2000 \\
\hline \multicolumn{5}{|l|}{ Lores } \\
\hline Hasta 1990 & $401,9 \mathrm{~mm}$ & Diciembre 1989 & $112,6 \mathrm{~mm}$ & Noviembre 1974 \\
\hline Desde 1990 & $355,0 \mathrm{~mm}$ & Enero 1996 & $92,8 \mathrm{~mm}$ & Noviembre 2006 \\
\hline
\end{tabular}

Fuente: AEMET. Delegación Territorial del Duero. Datos diarios de precipitación 
Son aspectos que lógicamente requieren un mayor tratamiento (segundo período), pero que se apuntan como posible hipótesis de cambio en relación con el comportamiento más incierto que está mostrando la dinámica atmosférica en las últimas décadas (cambio climático).

De Cervera hacia el este, las precipitaciones tienen importancia a partir de noviembre manteniéndose hasta febrero; en marzo disminuyen para incrementarse en abril/mayo, consolidando un máximo secundario más tangible. En las Montañas de Burgos, Ordunte, Obarenes y contacto oeste con el Páramo de la Lora, el régimen sigue siendo de otoño-invierno, pero con registros reducidos a 60-90 mm, salvo los lugares más norteños y altos (>100 mm). Por su parte, los valles de Las Loras y Obarenes tienen un régimen algo distinto. Los inviernos no son tan húmedos y las primaveras cobran cada vez más protagonismo, hasta el punto de igualar o incluso superar en cantidad a aquéllos (Barcina de los Montes, Frías, Trespaderne); además, abril es el máximo mensual. En ellos el régimen es de primavera-invierno. Únicamente en el contacto hacia la Bureba y Miranda la primavera es el período más lluvioso (75-85 mm/mes), y el otoño el máximo secundario $(40-60 \mathrm{~mm} / \mathrm{mes})$. El régimen se vuelve marcadamente equinoccial, más mediterráneo.

Por lo tanto, en la mitad oriental de la Cordillera se advierte un marcado carácter transicional que queda bien reflejado de norte a sur (Montañas de Burgos a la Bureba) como de oeste a este (Las Loras a la depresión de Miranda). Y tanta variedad como es obvio, se manifiesta también en la distribución y formas de los días de precipitación.

\subsection{El número de días de precipitación}

Muy ligado al cambio de regímenes pluviométricos en sentido zonal y meridiano, tiene lugar el descenso de días de precipitación. En todo el cordal Degaña/Laciana, Somiedo/Babia, Redes/Mampodre y Picos es de 160-180 días, con lo que precipita cerca de la mitad de los días del año. Posiblemente más en las cumbres. En cambio, en los valles se reduce a 130-150 días (Caboalles, Canseco, Porma, Riaño, Besande, Prioro), siendo los mismos que definen a la Montaña palentina (Cuadro 6).

Cuadro 6. Número medio de días de precipitación

OESTE DE CERVERA DE PISUERGA

\begin{tabular}{|c|c|c|c|c|c|c|c|c|c|c|c|}
\hline \multicolumn{12}{|c|}{ Montaña de León } \\
\hline \multicolumn{2}{|c|}{ Degaña/Laciana } & \multicolumn{3}{|l|}{ Babia } & \multicolumn{2}{|c|}{ Pajares/Piedrafita } & \multicolumn{3}{|c|}{ R. N. Mampodre } & \multicolumn{2}{|c|}{ Picos de Europa } \\
\hline Degaña & 166,9 & Genestosa & \multicolumn{2}{|c|}{177,4} & Pajares & 150,8 & \multicolumn{2}{|c|}{ Isoba/S.Isidro } & 171,3 & Llánaves $\mathrm{R}$. & 158,2 \\
\hline Leitariegos & 164,0 & Piedrafita B. & \multicolumn{2}{|c|}{155,4} & Busdongo & 131,5 & \multicolumn{2}{|c|}{ Cofiñal } & 153,6 & Lario-Buró & 134,3 \\
\hline Guímara & 156,8 & Torrebarrio & \multicolumn{2}{|c|}{127,8} & Piornedo & 110,0 & \multicolumn{2}{|c|}{ Puebla Lillo } & 140,1 & Boca de H. & 133,0 \\
\hline Caboalles & 135,4 & Huergas B. & \multicolumn{2}{|c|}{148,2} & Canseco & 146,3 & \multicolumn{2}{|c|}{ Maraña } & 131,2 & Prioro & 140,8 \\
\hline \multicolumn{12}{|c|}{ Montaña Palentina } \\
\hline \multicolumn{4}{|c|}{ Fuentes Carrionas } & \multicolumn{4}{|c|}{ La Pernía } & \multicolumn{4}{|c|}{ Braña/Híjar } \\
\hline \multicolumn{2}{|l|}{ Triollo } & \multicolumn{2}{|c|}{124,2} & \multicolumn{2}{|c|}{ Piedrasluengas } & \multicolumn{2}{|c|}{138,1} & \multicolumn{3}{|c|}{ Brañosera } & 109,5 \\
\hline \multicolumn{2}{|l|}{ La Lastra } & \multicolumn{2}{|c|}{122,9} & \multicolumn{2}{|c|}{ Camasobres } & \multicolumn{2}{|c|}{157,6} & \multicolumn{3}{|c|}{ Vallejo de Orbó } & 149,9 \\
\hline \multicolumn{2}{|c|}{ Emb. Camporredondo } & \multicolumn{2}{|c|}{133,7} & \multicolumn{2}{|c|}{ Lores } & \multicolumn{2}{|c|}{143,1} & \multicolumn{3}{|c|}{ S. Salvador de Cantamudá } & 130,7 \\
\hline \multicolumn{2}{|c|}{ Emb. Compuerto } & \multicolumn{2}{|c|}{148,5} & \multicolumn{2}{|c|}{ Tremaya } & \multicolumn{2}{|r|}{143,9} & Barruelo & ntullán & & 116,5 \\
\hline
\end{tabular}

ESTE DE CERVERA DE PISUERGA

\begin{tabular}{|lr|lr|lr|r|r|}
\hline \multicolumn{4}{|c|}{ Montañas de Burgos } & \multicolumn{2}{c|}{ Montes Vascos } \\
\hline \multicolumn{2}{|c|}{ Paramera/ Loras } & \multicolumn{2}{c|}{ Merindades } & \multicolumn{2}{c|}{ Montes Obarenes } & \multicolumn{2}{c|}{ Árcena/Valderejo } \\
\hline Polientes & 94,1 & Puerto Escudo & 156,3 & Barcina Montes & 119,8 & Sobrón \\
\hline Sta. Cruz Tozo & 105,1 & P. Ordunte & 145,2 & Oña & 99,6 & Bóveda & 115,0 \\
\hline Sargentes la Lora & 81,8 & Cabañas Virtus & 115,2 & Trespaderne & 105,6 & Salinas Añana \\
\hline Dobro & 93,0 & Castrobarto & 132,4 & Frías & 86,8 & Nanclares \\
\hline
\end{tabular}

Fuente: AEMET. Delegaciones Territoriales del Duero y País Vasco. Datos medios anuales.

Desde la $S^{a}$ de Orpiñas/Peña Prieta hasta Peña Labra los días inestables lentamente son menos. Su posición a sotavento del murallón de Picos, tiene consecuencias manifiestas. En las cabeceras del Carrión y Pisuerga se reducen a120-150 días, y en su tramo más oriental a 100-130 días (comarcas de Mudá, San- 
tullán, Campóo de Aguilar). Esta mengua es cada vez más patente en la mitad oriental y hacia la Cuenca del Duero. Salvo en Valnera y Ordunte (130-140 días), en las cimas de Las Loras, Paramera y Obarenes rondan los 100-120 días, mientras que en las combes (Albacastro, Humada, Valdelucio...), gargantas (Rudrón, Ebro, Oña, Purón...), y llanuras (Villarcayo-Tobalina, Miranda, Bureba), los 80-100 días.

Las mismas diferencias se advierten en su distribución mensual. En la montaña leonesa el mes que más precipita es siempre diciembre seguido de enero (medias 17-20 días), y de octubre a mayo todos los meses superan los 15 días. En los valles (Laciana, Luna, Porma, Riaño...) se reduce (11-15 días), al igual que en la Montaña palentina ( 15 días áreas más expuestas y no todos los meses del invierno). Lugares como Lores, Polentinos, Camporredondo, Abadía de Lebanza o Santa $\mathrm{M}^{\mathrm{a}}$ de Redondo, ningún mes alcanza el citado umbral a pesar de su altitud (más de $1.200 \mathrm{~m}$ ). Es evidente el menor número de jornadas lluviosas en este tramo de la cordillera. Lo mismo sucede desde Las Loras hasta los Montes Vascos, si bien aquí el máximo es ya primaveral. Salvo en las Montañas de Burgos (13-15 días) y el Páramo de la Lora (10-12 días), que continua siendo invernal (enero), en el resto se produce en abril o mayo.

El relieve fomenta la diversidad espacial y agudiza los contrastes. De igual forma que también a él se debe la importancia de los días de nieve en buena parte del año.

\subsection{La importancia de la nieve}

La nieve es el verdadero atributo de la montaña. Cuando se cubren de blanco sus cumbres, la cordillera destaca más que nunca, y esto sucede todos los años. El período de nevadas viene a coincidir con el de precipitaciones más abundantes, y su origen está ligado al paso de coladas árticas, vaguadas polares profundas del NO y circulaciones retrógradas. Son pues factores dinámicos los que delimitan su período temporal, pero la intensidad de las mismas e incluso su probabilidad de ocurrencia depende más de la energía del relieve y sus diferentes exposiciones, factores geográficos. Su influjo es más evidente en los equinoccios, cuando situaciones atmosféricas generales para amplios territorios peninsulares sólo las producen en el ámbito de esta cordillera. Por lo tanto, su probabilidad de aparición, intensidad, distribución y permanencia depende más de factores estrictamente morfológicos.

Aunque nieva en toda ella, existe una clara diferencia zonal (Cuadro 7, Figura 5). En su mitad occidental las nevadas duplican o triplican a las de su mitad oriental. No obstante, el sector donde más nieva no es el más noroccidental, sino el comprendido entre Braña Caballo y Ftes. Carrionas (de Pajares a San Glorio). Aquí se ubican las estaciones de esquí más importantes de la cordillera ${ }^{4}$ y nieva unos 50-65 días de media. En las cabeceras de los valles (desde el Sil al Pisuerga) se reduce a 30-45 días (1.200-1.300 m), y en su sector oriental (salvo las Montañas de Burgos) son inferiores en todos los casos a los 25 días, a veces bastante menos.

Están presentes de octubre a mayo (7-8 meses) o incluso de junio a septiembre en los enclaves mejor expuestos, si bien en estos últimos meses no tienen la misma intensidad ni frecuencia. Son nevadas poco representativas pero sí indicadoras del frío que llega a hacer. Las de mayo son más importantes (media 25 días) que las de octubre (13 días), pero sus valores ocultan la frecuencia real, pues hay años con más de 10 nevadas y otros muchos sin ellas. Las de junio y septiembre tienen promedios inferiores a 1 día, y ello en la parte occidental de la cordillera. La posibilidad de nevar en verano existe, pero sucede con tal relajación que entra dentro de lo excepcional ${ }^{5}$.

Así pues, las nevadas son más intensas de noviembre a abril, la mitad de los meses del año, con medias por encima de 5 días/mes, y superando bastantes la decena en el centro del invierno (Leitariegos, Piedrafita de B., Huergas de B., Pajares, S. Isidro, Llánaves, Piedrasluengas, Brañosera...). De diciembre a marzo se producen el $65 \%$ y es habitual que superen a los días de lluvia ${ }^{6}$. Tampoco son extraños años con 15-25 nevadas en alguno de estos meses. En cambio, en la mitad oriental la nieve es importante a partir de 1000 m, superando 20 o 30 días/año las áreas más septentrionales de Burgos (Pto. del Escudo), pues en los valles se reduce a 10-15 días, perdiendo representatividad por debajo de $700 \mathrm{~m}$, con medias inferiores a 10 días (Cuadro 7).

\footnotetext{
4 Valgrande-Pajares, Ftes de Invierno, San Isidro, Alto Campóo, Lunada esquí, Tres Provincias/S. Glorio.

5 En 13 observatorios leoneses y en 3 palentinos ha nevado en verano: 1932 (Torrebarrio, Rabanal de Luna, Riolago, Cofiñal, Riaño), 1952 (Besande, Riolago, Piornedo) y 1956 (Cofiñal, Piornedo). Desde 1990 a la actualidad sólo en Lores (2007). Son situaciones que no se descarta que puedan repetirse.

6 Piornedo en diciembre-1960 tuvo 18 nevadas de 20 de precipitación; Leitariegos en enero-1963 todo fueron nevadas, un total de 25; Prioro en enero-1972 tuvo 21 de 23 y en marzo-1975, 16 de 24; Besande en febrero-1968 fueron 19 de 21 , etc...
} 


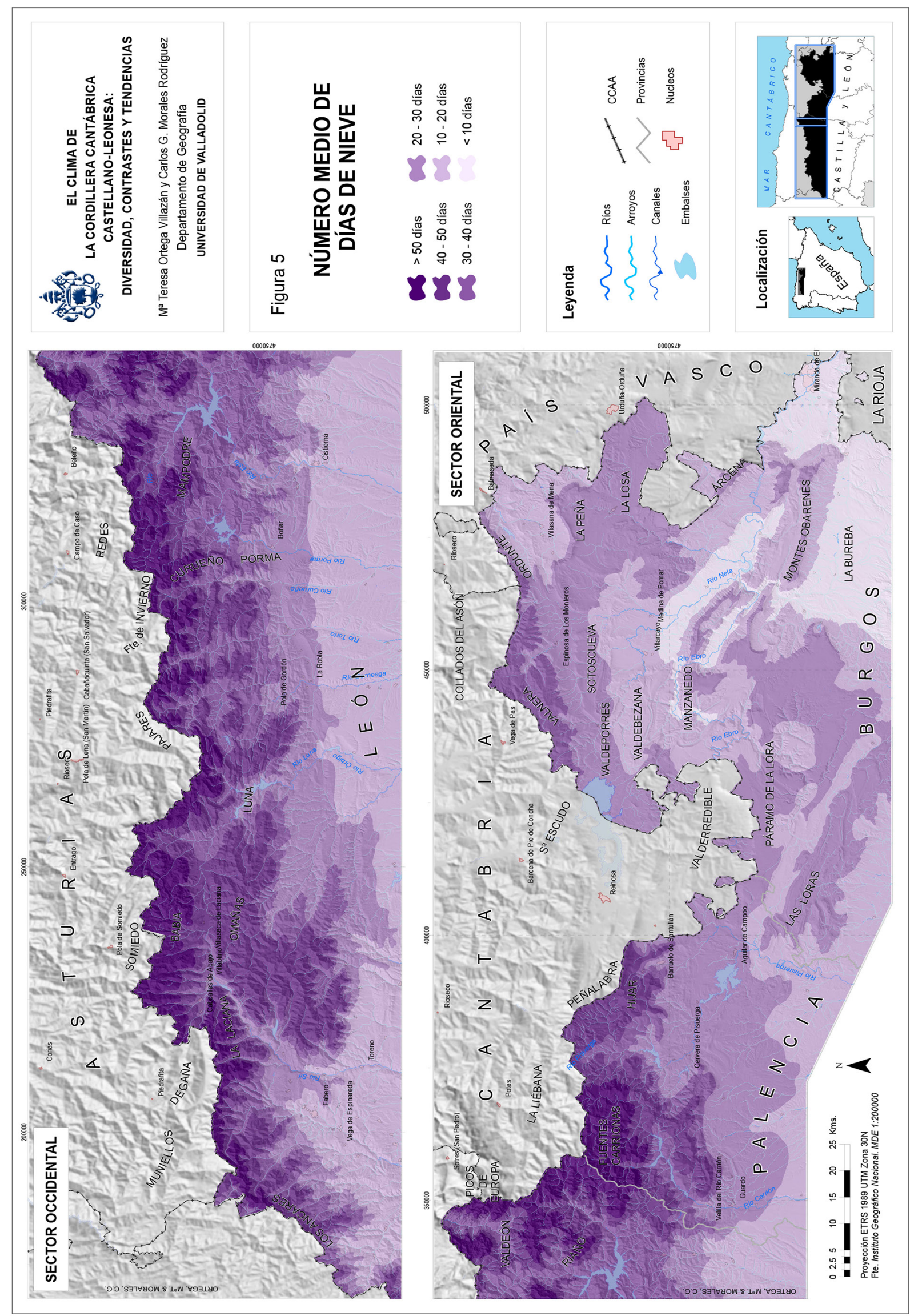


Cuadro 7. Número medio de días de nieve

OESTE DE CERVERA DE PISUERGA

\begin{tabular}{|c|c|c|c|c|c|c|c|c|c|c|}
\hline \multicolumn{11}{|c|}{ Montaña de León } \\
\hline \multicolumn{2}{|c|}{ Degaña/Laciana } & \multicolumn{2}{|c|}{ Babia } & \multicolumn{2}{|c|}{ Pajares/Piedrafita } & \multicolumn{3}{|c|}{ R. N. Mampodre } & \multicolumn{2}{|c|}{ Picos de Europa } \\
\hline Degaña & 51,7 & \multicolumn{2}{|l|}{ Genestosa } & Pajares & 45,0 & \multicolumn{2}{|c|}{ Isoba S.Isidro } & 64,0 & Llánaves R. & 54,2 \\
\hline Leitariegos & 56,1 & \multicolumn{2}{|l|}{ Piedrafita B. } & Busgongo & 33,2 & \multicolumn{2}{|c|}{ Cofiñal } & 52,5 & Lario-Burón & 35,0 \\
\hline Caboalles A. & 21,4 & Torrebarrio & 39,7 & Piornedo & 38,5 & \multicolumn{2}{|c|}{ Puebla Lillo } & 45,2 & Boca de $\mathrm{H}$. & 29,2 \\
\hline S. Miguel Lac. & 18,4 & Huergas B. & 43,4 & Canseco & 46,5 & \multicolumn{2}{|c|}{ Maraña } & 39,4 & Prioro & 36,5 \\
\hline \multicolumn{11}{|c|}{ Montaña Palentina } \\
\hline \multicolumn{3}{|c|}{ Fuentes Carrionas } & \multicolumn{4}{|c|}{ La Pernía } & \multicolumn{4}{|c|}{ Braña/Híjar } \\
\hline \multicolumn{2}{|l|}{ Triollo } & 38,8 & \multicolumn{2}{|c|}{ Piedrasluengas } & \multicolumn{2}{|c|}{53,6} & \multicolumn{3}{|l|}{ Brañosera } & 37,5 \\
\hline \multicolumn{2}{|l|}{ La Lastra } & 42,0 & \multicolumn{2}{|l|}{ Camasobres } & \multicolumn{2}{|c|}{47,0} & \multicolumn{3}{|c|}{ Vallejo de Orbó } & 42,2 \\
\hline \multicolumn{2}{|c|}{ Emb. Camporredondo } & 33,8 & \multicolumn{2}{|l|}{ Lores } & \multicolumn{2}{|c|}{42,3} & \multicolumn{3}{|c|}{ S. Salvador de Cantamudá } & 39,9 \\
\hline \multicolumn{2}{|c|}{ Emb. Compuerto } & 35,0 & \multicolumn{2}{|l|}{ Tremaya } & \multicolumn{2}{|c|}{44,4} & \multicolumn{3}{|c|}{ Barruelo de Santullán } & 25,1 \\
\hline
\end{tabular}

ESTE DE CERVERA DE PISUERGA

\begin{tabular}{|c|c|c|c|c|c|c|c|}
\hline \multicolumn{6}{|c|}{ Montañas de Burgos } & \multirow{2}{*}{\multicolumn{2}{|c|}{$\begin{array}{l}\text { Montes Vascos } \\
\text { Árcena/Valderejo }\end{array}$}} \\
\hline \multicolumn{2}{|c|}{ Paramera/ Loras } & \multicolumn{2}{|c|}{ Merindades } & \multicolumn{2}{|c|}{ Montes Obarenes } & & \\
\hline Polientes & 20,2 & Puerto del Escudo & 33,3 & Barcina de Mtes. & 17,1 & Sobrón & 12,3 \\
\hline Sta. Cruz del Tozo & 19,4 & Puerto Ordunte & 30,2 & Oña & 10,0 & Bóveda & 16,0 \\
\hline Sargentes la Lora & 18,5 & Cabañas Virtus & 23,0 & Trespaderne & 9,2 & Salinas Añana & 10,3 \\
\hline Dobro & 18,3 & Castrobarto & 19,7 & Frías & 8,8 & Nanclares & 11,0 \\
\hline
\end{tabular}

Fuente: AEMET. Delegaciones Territoriales del Duero y País Vasco. Datos medios anuales.

En la mayor parte de los observatorios el mes más nivoso es enero (70\%), seguido a larga distancia de febrero $(27,1 \%)$ y diciembre $(2,9 \%)$. La razón está en las situaciones dinámicas de ese momento, con mayor frecuencia de retrógrados y vaguadas árticas, unido al enfriamiento acumulado de gran parte del invierno. Lo que varía es la periodicidad de las nevadas según el sector de la cordillera. De todas formas, salvo en la mitad occidental, no representan unos umbrales muy elevados respecto al total de días de precipitación, aunque pueda haber años que sí suceda. En los lugares más nivosos, de noviembre a abril suponen siempre porcentajes por encima del 35\%; aunque en el período central del invierno del $50-75 \%$. En las áreas menos nivosas y a 800-900 m representan el 25-35\% de los días de precipitación; a menor altitud (600-700 m) sólo el 15-25\%, salvo en los valles con porcentajes inferiores al 15\% (Mena, Tobalina).

$\mathrm{El}$ análisis de la frecuencia de años muy nivosos revela que no siempre nieva lo que cabe esperar para una montaña de esta envergadura. Todos los años a 1.200-1.300 m se producen más de 20 nevadas, y el $80-90 \%$ de los mismos más de 30. Pero años con más de 50 representan un 20-45\% y sólo un 5-10\% los de más de 70 nevadas $^{7}$. Estos valores en la mitad oriental son impensables. De hecho, en los sectores deprimidos de Obarenes nunca se ha contabilizado un año con más de 20 nevadas.

La producción de nevadas año a año no es nada homogénea. Desde 1940 a la actualidad la alternancia de años nivosos y poco nivosos es algo habitual. En los primeros las cumbres permanecen blancas hasta bien adentrada la primavera y pequeños neveros se mantienen a comienzos del verano. Es difícil estimar su permanencia pero algunos autores han señalado valores por encima de 200 días (Lautensach, 1956: 448). En cambio, los años poco nivosos no alcanzan ni la veintena. Ello evidencia lo cambiante de la dinámica atmosférica. No obstante, desde 1990 a nuestros días se denota un descenso manifiesto en relación con la mayor variabilidad climática de las últimas décadas. Cada vez es más raro que se produzcan más de 40 nevadas/año (Cuadro 8). Lo cual no es óbice para que no puedan volver a producirse, caso del invierno pasado y el presente, muy nivosos en gran parte de Europa.

7 Incluso algún año supera el centenar, pero no es lo habitual. Sólo ha ocurrido en Leitariegos en 1963, Degaña en 1979 y San Isidro en 1984. Esto favorece períodos de innivación significativos. 
Cuadro 8. Días de nieve según períodos temporales

\begin{tabular}{|c|c|c|c|}
\hline Estaciones & Observaciones & Máximo días & Mínimo días \\
\hline \multicolumn{4}{|l|}{ Genestoso } \\
\hline Hasta 1990 & 21 años (de 29) por encima de 40 días & 75 (1970 y 1972$)$ & $29(1961)$ \\
\hline Desde 1990 & 10 años (de 23) por encima de 40 días & $66(2010)$ & $23(1997)$ \\
\hline \multicolumn{4}{|l|}{ Canseco } \\
\hline Hasta 1990 & 16 años (de 26) por encima de 40 días & 77 (1972) & $27(1967$ y 70$)$ \\
\hline Desde 1990 & 3 años (de 23) por encima de 40 días & 48 (1999) & 32 (1993) \\
\hline \multicolumn{4}{|l|}{ Maraña } \\
\hline Hasta 1990 & 8 años (de 55) con menos de 35 días & $68(1972)$ & $14(1961)$ \\
\hline Desde 1990 & 11 años (de 21) con menos de 35 días & $67(2010)$ & $18(1997)$ \\
\hline \multicolumn{4}{|l|}{ Boca de Huérgano } \\
\hline Hasta 1990 & 21 años (de 37) con más de 40 días & $57(1985)$ & $15(1961)$ \\
\hline Desde 1990 & 2 años (de 22) con más de 40 días & $57(1991)$ & $11(1997)$ \\
\hline \multicolumn{4}{|l|}{ Besande } \\
\hline Hasta 1990 & 5 años (de 40) con menos de 40 días & 76 (1979) & $19(1961)$ \\
\hline Desde 1990 & 11 años (de 19) con menos de 40 días & $47(1992)$ & $15(1993$ y 97$)$ \\
\hline \multicolumn{4}{|l|}{ Triollo } \\
\hline Hasta 1990 & 21 años (de 36) con más de 40 días & $68(1984)$ & $22(1973)$ \\
\hline Desde 1990 & 3 años (de 22) con más de 40 días & $52(1996)$ & 24 (1999) \\
\hline \multicolumn{4}{|l|}{ Lores } \\
\hline Hasta 1990 & 3 años (de 24) con menos de 35 días & $69(1972)$ & $23(1989)$ \\
\hline Desde 1990 & 9 años (de 20) con menos de 35 días & $55(2005)$ & 19 (1997) \\
\hline
\end{tabular}

Fuente: AEMET. Deleogación Territorial del Duero. Datos diarios de precipitación.

La reducción de nevadas desde hace dos décadas en todos los observatorios supera el 20\%. Además, se aprecia un cierto cambio en la evolución de su régimen, pues aunque siga siendo el máximo invernal se advierte un incremento de las de abril (Cuadro 9). A ello se añade su poca presencia en meses periféricos, al reducirse de forma drástica en junio y septiembre.

Cuadro 9. Evolución de los días de nieve según períodos

\begin{tabular}{|l|ccccccccccc|c|c|}
\hline Estación & E & F & M & A & M' & J & J' & A' & S & O & N & D & Total \\
\hline Genestoso & & & & & & & & & & & & \\
Hasta 1990 & 9,3 & 9,1 & 8,9 & 6,3 & 3,2 & 0,2 & 0,0 & 0,1 & 0,2 & 1,7 & 4,9 & 7,7 & 51,7 \\
Desde 1990 & 7,3 & 6,7 & 5,2 & 7,1 & 1,9 & 0,0 & 0,0 & 0,0 & 0,1 & 1,0 & 4,7 & 6,3 & 40,2 \\
Canseco & & & & & & & & & & & & & \\
Hasta 1990 & 7,3 & 8,3 & 7,7 & 7,2 & 3,4 & 0,2 & 0,0 & 0,0 & 0,4 & 2,2 & 5,0 & 8,2 & 49,9 \\
Desde 1990 & 6,9 & 4,7 & 3,8 & 8,5 & 2,2 & 0,1 & 0,0 & 0,0 & 0,3 & 1,0 & 4,4 & 6,7 & 38,6 \\
Maraña & & & & & & & & & & & & & \\
Hasta 1990 & 7,8 & 7,1 & 6,1 & 5,1 & 2,1 & 0,2 & 0,0 & 0,0 & 0,1 & 1,1 & 4,4 & 7,1 & 41,2 \\
Desde 1990 & 7,7 & 6,9 & 5,4 & 4,9 & 1,7 & 0,0 & 0,0 & 0,0 & 0,0 & 0,6 & 3,8 & 5,7 & 36,6 \\
Boca de Huérgano & & & & & & & & & & & & \\
Hasta 1990 & 7,5 & 6,5 & 5,2 & 3,7 & 1,1 & 0,1 & 0,0 & 0,0 & 0,1 & 0,8 & 3,3 & 6,3 & 34,6 \\
Desde 1990 & 5,8 & 4,8 & 3,2 & 2,9 & 0,7 & 0,0 & 0,0 & 0,0 & 0,0 & 0,4 & 2,1 & 3,8 & 23,7 \\
Besande & & & & & & & & & & & & & \\
Hasta 1990 & 10,0 & 9,9 & 7,9 & 6,5 & 2,7 & 0,3 & 0,0 & 0,0 & 0,3 & 2,4 & 5,4 & 8,6 & 54,1 \\
Desde 1990 & 5,0 & 4,1 & 3,6 & 4,1 & 1,3 & 0,0 & 0,0 & 0,0 & 0,2 & 0,4 & 2,6 & 3,2 & 24,6 \\
Triollo & & & & & & & & & & & & \\
Hasta 1990 & 8,1 & 8,6 & 6,0 & 4,2 & 2,0 & 0,2 & 0,0 & 0,0 & 0,1 & 1,6 & 4,6 & 7,3 & 42,7 \\
Desde 1990 & 7,5 & 5,4 & 4,5 & 5,6 & 2,0 & 0,1 & 0,0 & 0,0 & 0,2 & 1,6 & 3,6 & 4,5 & 34,9 \\
Lores & & & & & & & & & & & & \\
Hasta 1990 & 8,4 & 8,3 & 8,2 & 6,8 & 2,2 & 0,1 & 0,0 & 0,0 & 0,1 & 1,2 & 4,7 & 7,4 & 47,3 \\
Desde 1990 & 8,3 & 6,7 & 5,4 & 4,9 & 1,2 & 0,0 & 0,0 & 0,2 & 0,0 & 0,8 & 3,4 & 6,1 & 37,0 \\
\hline
\end{tabular}

Fuente: AEMET. Delegación Territorial del Duero. Datos diarios de precipitación. 
Pese a todo, los espesores de nieve algunos años son realmente importantes ${ }^{8}$, y normalmente se mantiene hasta junio. De hecho la temporada de esquí de travesía se cierra en Peña Prieta a últimos de mayo o principios de junio con unos 550-650 m de desnivel esquiable en condiciones aceptablemente buenas. Pero lógicamente esto no sucede todos los años. De San Isidro hacia el oeste como las temperaturas son menos frías y se mete la niebla con mayor frecuencia la nieve dura mucho menos, como sucede en el Pto. Pajares, aparte de su menor altitud $(1.375$ m). Sin embargo, en Braña Caballo la nieve se acumula en mayor medida a pesar de su ubicación a sotavento. Este tramo de divisoria (Cellón, Estorbín, Tres Concejos...), evita que entre la niebla y es más frío. Aquí es frecuente ver neveros hasta verano.

El sector que ofrece mejores condiciones para su permanencia es entre San Isidro y Alto Campóo, y posiblemente el tramo Coriscao-Peña Prieta (Pto. San Glorio), y ello por varias razones. Este conjunto de altas peñas límite entre Cantabria y León está más alejado del mar, lo que favorece menores temperaturas. Además, al tener al norte a Torrecerredo que actúa de barrera frente a las borrascas, disfruta de una nieve de mejor calidad. Por su posición, queda más a resguardo del aire templado en situación de foehn, de los vientos más fuertes (área de Leitariegos), o de aquellas situaciones del SO que generan más agua que nieve y, por tanto, fusiones inevitables.

Por lo tanto, es cierto que existen áreas de buena acumulación nívea pero el análisis realizado pone de manifiesto que su evolución varía mucho de unos años a otros. Según la forma de penetrar las situaciones dinámicas unas veces nieva más en S. Isidro, con situaciones del NO, y otras en Alto Campóo, si dominan las del NNE o NE. Pero la dinámica atmosférica es voluble de un año a otro, y no siempre se tiene la certeza de que se vayan a producir nevadas intensas que permitan el óptimo funcionamiento de las estaciones, unos cuatro meses por temporada ${ }^{9}$.Además, desde la década del 90 se advierte una tendencia a su disminución en distintos puntos de la cordillera. Cada vez es más habitual asegurar y/o prolongar el uso de las estaciones con cañones de nieve ${ }^{10}$. Y tanta solicitud de nuevas instalaciones no hace sino corroborar la falta de nieve que existe de forma natural.

Hay diversos estudios que corroboran esta idea. Para el caso de Castilla y León, desde el último cuarto del s. XX se advierte un aumento de las temperaturas medias anuales, sobre todo por el comportamiento térmico de la primavera y el verano, estimado en $0,05^{\circ} \mathrm{C} / a n ̃ o$. Hay una tendencia creciente en los valores de las anomalías de las máximas, mínimas y medias, tanto anuales como estacionales (Morales et al., 2005), lo que concuerda con los resultados obtenidos en otras regiones españolas y europeas (Schönwise et al., 1997).Esta tendencia se debe a un incremento (tanto en las máximas como en las mínimas diarias) de la frecuencia anual de valores extremos más altos y a una disminución de la frecuencia anual de valores extremos más bajos (Ortega et. al, 2006). Se aprecia una reducción del número de heladas y un incremento del número de días con máximas más altas. Directamente relacionado con ello está el comportamiento de la presión atmosférica a nivel del suelo, que evidencia un incremento de las situaciones anticiclónicas a expensas de las ciclónicas a lo largo del año (Labajo et al., 2004, 2008, 2009).Esta mayor frecuencia anticiclónica implica más radiación solar, contribuyendo al aumento detectado en la temperatura del aire en las últimas décadas tanto en estudios globales (Jones et al., 2003; IPCC, 2007) como de escala regional (Forland et al., 2001; Galán et al., 2001).

Según el Modelo del Hadley Centre for Climate Prediction and Research, UK Met Office, las previsiones de cambio entre las condiciones presentes y el 2080 (modelo Hadley3) y los escenarios de emisiones de gases de efecto invernadero del IPCC reflejan una disminución de la precipitación del 15\% y un aumento de la temperatura de hasta $4^{\circ} \mathrm{C}$ en la zona de la Cordillera Cantábrica. Así mismo, los escenarios de cambio climático regionalizados para España, que coordinó en su día I.N.M, sobre la alta montaña preveían aumentos de la temperatura máxima en invierno de unos $2^{\circ} \mathrm{C}$ a partir de 2040 , sobre todo en noviembre y marzo (lo que contribuiría al acortamiento de la temporada de esquí).

Actualmente hay una serie de factores que justifican la fuerte irregularidad de las nevadas. Basta mirar los balances de las temporadas de los últimos 10 años. La alternancia de años muy buenos (2005/2006, 2008/2009) con otros malos es lo más frecuente (2006/2007; 2007/2008 no abrieron hasta Semana Santa; 2009/2010; 2011/2012 hasta febrero).Esta irregularidad siempre ha existido, es algo propio del clima,

8 Se han estimado en San Glorio entre 40-110 cm en cotas de 2.000-2.450 m de altitud. (Nota de prensa).

9 La temporada 2010-2011 Fuentes de Invierno permaneció abierta 82 días (67,8\%), y registró 38.167 esquiadores; Valgrande-Pajares 115 días (95\%) con 81.739 esquiadores (notas de prensa).

10 Desde hace años si no fuera por ellos las estaciones no serían rentables. No son extraños proyectos de nuevas instalaciones (150 cañones en Alto Campóo desde 2008; solicitudes para Ftes. de Invierno, etc.). Desde 1985 que comenzaron a instalarse en España a hoy día su número no para de aumentar habiendo en la actualidad más de 4.500, con capacidad para innivar 375,12 Km (datos ATUDEM.org). 
pero hoy día se manifiesta de forma más llamativa. La nieve es cada vez más un recurso imprevisible, lo que hace difícil comprender la viabilidad de nuevos proyectos, y previene de los grandes gastos que habrá que realizar en adelante para mantener y mejorar las ya existentes ${ }^{11}$.

\subsection{Contrastes pluviométricos durante los veranos a lo largo de la cordillera}

Aunque la llegada del estío trae un descenso importante de las lluvias, éstas se mantienen en general con valores altos. El mayor dominio de dinámicas tropicales justifica esta reducción, sobre todo en julio y agosto, pues junio y septiembre conservan medias de 60-90 mm en su mitad occidental y de 40-60 mm en su mitad suroriental.

En esta época la Cantábrica sigue siendo una pantalla de humedad lo que la distingue del resto de las montañas de Castilla y León. Sus peñas suelen ser el límite más meridional del paso de frentes fríos. Pero este mantenimiento de la humedad no es homogéneo a lo largo de toda ella. Hay bastantes espacios que aun con índices elevados gozan de una aridez manifiesta. Hay razones que justifican esta aparente paradoja.

Algunos de los métodos tradicionales de delimitación de aridez consideran que ésta no existe cuando se superan los $30 \mathrm{~mm}$ de precipitación mensual (Lautensach), o es superior la precipitación del mes al doble de las temperaturas de ese mismo mes (Gaussen). Según estas premisas son realmente escasos los lugares con aridez pues predominan medias por encima de 30-40 mm (Cuadro 10). Sin embargo, gran parte de su mitad oriental la padece pese a que sus registros sean elevados.

Cuadro 10. Precipitaciones medias estivales (mm). Julio/ Agosto

OESTE DE CERVERA DE PISUERGA

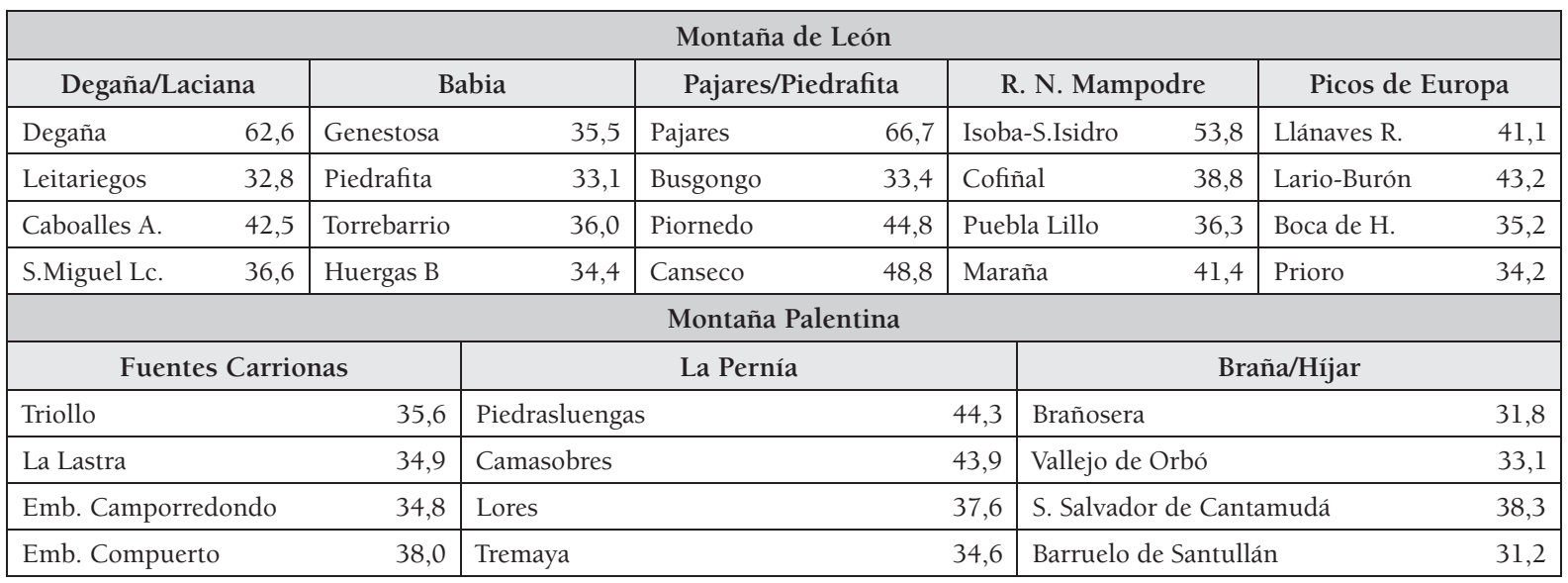

ESTE DE CERVERA DE PISUERGA

\begin{tabular}{|c|c|c|c|c|c|c|c|}
\hline \multicolumn{6}{|c|}{ Montañas de Burgos } & \multirow{2}{*}{\multicolumn{2}{|c|}{$\frac{\text { Montes Vascos }}{\text { Árcena/Valderejo }}$}} \\
\hline \multicolumn{2}{|c|}{ Paramera/ Loras } & \multicolumn{2}{|c|}{ Merindades } & \multicolumn{2}{|c|}{ Montes Obarenes } & & \\
\hline Polientes & 29,7 & Pto. del Escudo & 60,5 & Barcina de Montes & 36,8 & Sobrón & 39,1 \\
\hline Sta. Cruz del Tozo & 25,3 & Puerto de Ordunte & 46,8 & Oña & 37,1 & Bóveda & 32,6 \\
\hline Sargentes la Lora & 28,1 & Cabañas Virtus & 33,3 & Trespaderne & 35,2 & Salinas de Añana & 33,0 \\
\hline Dobro & 23,6 & Castrobarto & 35,4 & Frías & 38,5 & Nanclares & 32,6 \\
\hline
\end{tabular}

Fuente: AEMET. Delegaciones Territoriales del Duero y País Vasco. Datos medios anuales.

En la alta montaña leonesa y palentina la aridez no existe como tal (medias $>50 \mathrm{~mm}$ ) y es mejor hablar de período de reducción de lluvias. El verano más que una estación bien definida parece una primavera, inestable, lluviosa, con precipitaciones inapreciables y cielos muchos días cubiertos. Sin embargo, a partir de Brañosera la aridez adquiere síntomas muy evidentes, porque las temperaturas son más elevadas y la realidad ecológica muestra unos paisajes distintos. No obstante, en los altos de Valnera-Ordunte y el inmediato pasillo de Espinosa no hay aridez, lo que no deja de tener su singularidad dentro del sector

11 En los últimos 10 años se han invertido en las estaciones de la cordillera 95.343.930€, aunque en los dos últimos se han reducido, acorde al contexto económico actual (datos ATUDEM.org, 2013). 
oriental. Más hacia el sur la cosa cambia. Las depresiones de Villarcayo-Medina de Pomar y los valles de Valdivieso y Obarenes no son tan húmedos, pero tampoco padecen aridez marcada. En cambio, en las Parameras y Las Loras ésta es manifiesta, aunque atenuada.

Si se analiza la frecuencia de años con precipitaciones según distintos umbrales se aprecia que no todos los veranos tienen registros elevados, incluso las montañas más húmedas. En éstas un 10-20\% de los años ningún mes alcanza $30 \mathrm{~mm}$; un 40-45\% sólo un mes supera los $30 \mathrm{~mm}$; un 30-50\% los dos meses superan los $30 \mathrm{~mm}$, y sólo un 20\% los $40 \mathrm{~mm}$. Cierto es que algunos veranos registran $150-200 \mathrm{~mm} / \mathrm{mes}$, pero no sucede con la frecuencia esperada, y en igual proporción hay años que no alcanzan ni $20 \mathrm{~mm}$. Por lo tanto, las montañas más húmedas también disfrutan de veranos secos.

En la mitad oriental lo habitual es que más del $50 \%$ de los años un mes no alcance los $30 \mathrm{~mm}$, y que no lo haga ninguno más del 30\%. Tampoco es extraño que sus índices sean superiores a los de septiembre (30-50\%), y que altos registros no sean exclusivos de estas sierras sino de bastantes puntos de la Bureba. Todo ello tiene mucho que ver con la forma de producirse las lluvias.

Éstas no se deben a un número elevado de días (aunque haya años que sí suceda), ni se distribuyen de forma homogénea a lo largo del mes. Por el contrario, responden a fuertes tormentas (dinámicas mixtas de crestas Tm con baja térmica superficial y aire frío en altura de alguna vaguada o gota fría Pm), o a descargas más débiles durante varias jornadas asociadas al paso de vaguadas. Aunque contribuyan a elevar los índices medios, su papel como mitigadoras de la aridez queda bastante en entredicho.

Las precipitaciones se reparten en un número de días no muy alto. Medias de 6-9 días/mes en la Montaña leonesa y palentina, de 4-6 días en los valles de la mitad occidental; de 2-4 días en la Paramera y las Loras, de 5-8 días en las Montañas de Burgos, y de 3-6 días en los Obarenes y Montes Vascos. Sólo la concentración de lluvias en varios momentos justifica lo elevado de los umbrales medios del estío.

Pese a todo, estas montañas disfrutan algunos años de veranos muy lluviosos, con más de 15-20 días/ mes, o con más de 30 a lo largo del estíio ${ }^{12}$. Son los veranos inestables, húmedos y frescos. Pero también hay otros que no computan ni 5 días/mes. La variabilidad interanual es muy importante, y en el fondo no deja de indicarnos la proximidad del dominio mediterráneo.

Las lloviznas, rocíos, y sobre todo, nieblas y neblinas desempeñan un papel muy importante como compensadores de la aridez, sobre todo en las estribaciones más orientales. Cuando los vientos del norte arrastran aire húmedo hacia el sur, las peñas quedan cubiertas por nieblas de advección que hacia el interior se desvanecen en sus efectos, de manera que a Las Loras y Obarenes ya poco afectan, aunque sí se percibe su influjo por la densa brumosidad que generan. Más frecuentes son las nieblas de irradiación que en el despertar del día se agolpan en los fondos (mar de nubes) mientras que en los altos brilla el sol. Igualmente, si el enfriamiento nocturno es importante y la humedad alta, en los amaneceres es habitual ver la hierba mojada. Medias de 20-40 días de rocío caracterizan a gran parte de las Loras y el Páramo de Masa, reduciéndose por debajo del primer umbral en el contacto con la cuenca (Ortega, 1995: 930).

Estas precipitaciones ocultas en muchos valles son de frecuencia casi cotidiana, lo que supone un aporte adicional de humedad al suelo y suplen las menores lluvias de estos meses. Además, tienen una respuesta ecológica clara al mantener el verdor de la vegetación retrasando su agostamiento, al tiempo que justifica la presencia de manchas de hayedos en alineaciones bastante meridionales de Las Loras (Valdelucio) y Obarenes ( $S^{a}$ de Oña, Miraveche, Buey, Verdina).

\section{CONCLUSIONES}

La Cordillera Cantábrica pese haber sido caracterizada como la única montaña oceánica de España, no es climáticamente homogénea. Posee un clima único para la latitud tan meridional en la que se ubica, mostrando un comportamiento dispar según vertientes, al variar el grado de exposición a los influjos oceánicos, y por su marcada disposición zonal, al existir contrastes entre dos grandes mitades separadas por el virtual meridiano de Cervera de Pisuerga.

Su clima es tributario de su localización espacial, de sus caracteres morfológicos y de sus relaciones con la dinámica atmosférica; pero su diversidad morfoestructural es responsable de la gran cantidad de matices que en ella se descubren. Su vertiente castellana está formada por un conjunto de montañas (leonesa, palentina, burgalesa) diferentes entre sí, con rasgos propios y que las distinguen. Su marcada

12 Como el verano de 1983: 37 días en S.Isidro, 36 en Degaña y Piedrasluengas, 33 en Cofiñal, 31 Canseco, 25 en Prioro, 24 en Sta. Ma de Redondo y Lores, 14 en Sargentes...Pero no ha sido el único. 
prolongación zonal en gran parte lo justifica. También su progresivo alejamiento del influjo marino. Hay una clara transición meridiana en cada una de sus unidades, pero también en sentido NO-SE para el conjunto de toda ella. Como tal se distingue dentro del conjunto de la Cordillera, pero también respecto a otras montañas de Castilla y León. Además, su presencia individualiza el clima de las llanuras de Castilla.

También es una cordillera de contrastes, térmicos y pluviométricos, y a muy diferentes escalas. Contrastes entre la sombra y el sol, entre el día y la noche, entre las Altas Peñas y los valles, entre el frío y calor de los veranos, entre vertientes norte y sur, y entre su mitad occidental y oriental. Y este último aspecto quizá sea el más relevante.

Hacia el oeste, en las Montañas de León y Palencia, el clima es de montaña atlántica, frío en invierno, fresco en verano, con numerosas heladas, lluvioso todo el año, con abundantes nevadas y sin aridez. Hacia el este se marca una transición hacia la montaña mediterránea, bien perceptible desde las Montañas de Burgos a las llanuras castellanas. La progresiva desecación del aire en su discurrir hacia el interior, la menor intensidad de los frentes, la mayor sequedad atmosférica en situaciones de estabilidad..., son hechos cada vez más constatados. Por ello, determinados valles interiores en muchos aspectos apenas difieren de la Castilla de las llanuras, lo que le otorga una gran ambigüedad climática.

Finalmente, esta cierta indefinición se descubre en el análisis evolutivo que muestran las precipitaciones, sobre todo desde la década de los 90 a nuestros días. Llama la atención su irregularidad interanual, sobre todo durante los veranos, y la menor importancia que parecen tener las nevadas.

\section{BIBLIOGRAFÍA}

ALEXANDERSSON, H \& MOBERG, A. (1997): «Homogenization of Swedish Temperature Data. Part I: Homogenenity tets for linear trends». Int. Journal Climatologie, 17, pp. 25-34.

FEO PARRONDO, F. (2006): «Las estaciones de esquí en la cordillera Cantábrica». Investigaciones Geográficas, $\mathrm{n}^{\circ}$ 40. Alicante. pp. 119-139.

FORLAND, E.J.; HANSSEN-BAUER, I. (2001): «Changes in temperature and precipitation in the Norwegian arctic during the $20^{\text {th }}$ century». Detecting and Modelling Regional Climate Change (BRUNET et al. eds.). Springer-Verlag. Berlín. pp. 153-161.

GALÁN, et al. (2001): "Annual temperature evolution in the southern plateau of Spain from the construction of regional climate time series». Detecting and Modelling Regional Climate Change (BRUNET et al. eds.). Springer-Verlag. Berlín. pp. 119-131.

GARCÍA FERNÁNDEZ, J. (1986): El clima en Castilla y León. Ed. Ámbito. Valladolid.370 pp.

INTERGOVERNMENTAL PANEL ON CLIMATE CHANGE (IPCC):

- (2001): Third Assessment Report. Climate Change 2001.

- (2007): Fourth Assessment Report. Climate Change 2007.

JANSÁ CLAR, A. (1971): «Investigaciones del máximo pluviométrico de España peninsular». Revista de Geofísica, 3-4. pp. 173-249.

JONES, P.D. \& MOBERG, A.(2003): «Hemispheric and large scale surface air temperature variations: an extensive revision and an update 3 to 2001». Jnal. of Climate, 16. pp. 206-223.

LAUTENSACH, H.:

- (1956): «El ritmo de las estaciones en la Península Ibérica». Estudios Geográficos, nº 64. Madrid. pp. 443-461.

- (1962): «Características y ritmo anual de la temperatura en la Península Ibérica». Estudios Geográfcos, $\mathrm{n}^{\circ} 87$. Madrid. pp. 259-292.

LABAJO, J.L., ORTEGA, Ma T., MORALES, C., MARTíN, Q.y PIORNO, A.:

- (2004): «Primeros resultados del comportamiento de los valores extremos de la presión atmosférica al nivel del suelo, en Castilla y León». El Clima, entre el mar y la montaña. IV Congreso de la Asociación Española de Climatología (AEC). Santander. pp. 313-322.

- (2008): «Recent trends in the frequencies of extreme values of daily maximum atmospheric pressure at ground level in the central zone of the Iberian Peninsula». International Journal of Climatology. Volume 28, Issue 9. pp. 1227-1238.

- (2009): «Analysis of the behavior of the extreme values of minimum daily atmospheric pressure at ground level over the Spanish Central Plateau». Atmósfera 22. pp. 125-139.

MOUNIER, J.: 
- (1979a): «La diversité des climats océaniques de la Péninsule Ibérique». La Météorologie, VI, 16. París. pp. 205-227.

- (1979b): «Les origines du passage du domaine océanique ou domaine méditerranée dans la Péninsule Ibérique». Méditerranée. T. 36. pp. 3-17.

MORALES, C. (2002): El clima en los Montes Obarenes (Burgos). Transición y ambigüedad de un espacio montañoso de la Cordillera Cantábrica oriental. Inédito. $100 \mathrm{p}$.

MORALES, C. et al. (2005): «Recent trends and temporal behavior of thermal variables in the region of Castilla-Leon (Spain)». Atmósfera, 18. pp. 125-139.

ORTEGA, M ${ }^{a}$ T. \& MORALES, C. (1995): «Un clima de transición en alta montaña». En Aula activa de la naturaleza Arbejal. Junta de Castilla y León. pp. 43-62.

ORTEGA VILLAZÁN, $\mathrm{M}^{\mathrm{a}} \mathrm{T}$ :

- (1990): «El clima de la comarca Páramos». En Evolución, situación actual y perspectivas de la comarca Páramos (Burgos). Junta de Castilla y León. 316 p.

- (1992): Estudio geográfico del clima del sector norte de la Cordillera Ibérica. Ed. Universidad de Valladolid \& Junta de Castilla y León. 359 p.

- (1995): «Las precipitaciones inapreciables en los veranos de un sector de la vertiente meridional de la cordillera Cantábrica oriental: los páramos de la Lora y las Loras». VI Coloquio Ibérico de Geografía. Porto. pp. 927-934.

ORTEGA, $M^{a}$ T. et al. (2006): «Tendencias recientes de las frecuencias de los valores extremos de temperatura en Castilla y León». Clima, sociedad y Medio Ambiente. pp. 251-260.

ORTEGA VALCALCEL, J. (1974): La transformación de un espacio rural. Las Montañas de Burgos. Servicio de publicaciones de la Universidad de Valladolid. Valladolid. 531 p.

SCHÖNWISE, C.D. \& RAPP, J. (1997): Climate trends atlas of Europe. Kluwer Academic Publishers. Dordrecht. 228 p.

URIARTE, A. (1980): «La lluvia en la costa norte de la P. Ibérica». Lurralde 3. pp.103-107. 